\title{
Isolation, Structural Elucidation, Optical Resolution, and Antineuroinflammatory Activity of Phenanthrene and 9,10-Dihydrophenanthrene Derivatives from Bletilla striata
}

Di Zhou, ${ }^{\dagger}, \S$ Gang Chen,${ }^{\dagger}$ Yue-Ping Ma,${ }^{\dagger}$ Cun-Gang Wang, ${ }^{\dagger}$ Bin Lin,${ }^{\dagger}$ Yan-Qiu Yang, ${ }^{\perp}$ Wei Li,${ }^{\dagger} \S$ Kazuo Koike, ${ }^{\S}$ Yue Hou, ${ }^{*}$, and Ning $\mathrm{Li}^{*}, \dagger, \|$

${ }^{\dagger}$ School of Traditional Chinese Materia Medica, and ${ }^{\ddagger}$ School of Pharmaceutical Engineering, Shenyang Pharmaceutical University, Shenyang 110016, People's Republic of China

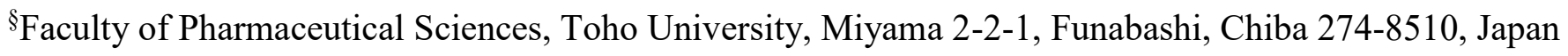

${ }^{\perp}$ College of Life and Health Sciences, Northeastern University, Shenyang 110004, People's Republic of China

\|State Key Laboratory for Chemistry and Molecular Engineering of Medicinal Resources, Guangxi Normal University, Guilin, People's Republic of China 


\section{List of Supporting Information}

S1. Chemical structure of bletillatin A (1).

S2. ${ }^{1} \mathrm{H}$ NMR $\left(600 \mathrm{MHz}\right.$, methanol- $\left.d_{4}\right)$ spectrum of bletillatin A (1).

S3. ${ }^{13} \mathrm{C}$ NMR $\left(150 \mathrm{MHz}\right.$, methanol- $\left.d_{4}\right)$ spectrum of bletillatin A (1).

S4. HSQC spectrum of bletillatin A (1).

S5. HMBC spectrum of bletillatin A (1).

S6. NOESY spectrum of bletillatin A (1).

S7. HRESIMS spectrum of bletillatin A (1).

S8. Chemical structure of bletillatin B (2).

S9. ${ }^{1} \mathrm{H}$ NMR $\left(600 \mathrm{MHz}\right.$, methanol- $\left.d_{4}\right)$ spectrum of bletillatin B (2).

S10. ${ }^{13} \mathrm{C}$ NMR (150MHz, methanol- $d_{4}$ ) spectrum of bletillatin B (2).

S11. HSQC spectrum of bletillatin B (2).

S12. HMBC spectrum of bletillatin B (2).

S13. NOESY spectrum of bletillatin B (2).

S14. HRESIMS spectrum of bletillatin B (2).

S15. Chemical structure of bletillatin C (3).

S16. ${ }^{1} \mathrm{H}$ NMR $\left(600 \mathrm{MHz}\right.$, methanol- $\left.d_{4}\right)$ spectrum of bletillatin C (3).

S17. ${ }^{13} \mathrm{C}$ NMR (150MHz, methanol- $d_{4}$ ) spectrum of bletillatin C (3).

S18. HSQC spectrum of bletillatin C (3).

S19. HMBC spectrum of bletillatin C (3).

S20. HRESIMS spectrum of bletillatin C (3).

S21. Chemical structure of bletillatin D (4).

S22. ${ }^{1} \mathrm{H}$ NMR $\left(600 \mathrm{MHz}\right.$, methanol- $\left.d_{4}\right)$ spectrum of bletillatin D (4).

S23. ${ }^{13} \mathrm{C}$ NMR (150MHz, methanol- $\left.d_{4}\right)$ spectrum of bletillatin D (4).

S24. HSQC spectrum of bletillatin D (4).

S25. HMBC spectrum of bletillatin D (4).

S26. HRESIMS spectrum of bletillatin D (4). 
S27. Acid hydrolysis of compound $\mathbf{3}$ and HPLC analysis for sugar residues.

S28. The experimental methods used for ECD calculations of compounds 1, 2, and 22.

S29. Optical resolution and determination of the absolute configuration of compound $\mathbf{5}$.

S30. Optical resolution and determination of the absolute configuration of compound $\mathbf{8}$.

S31. Optical resolution and determination of the absolute configuration of compound 9.

S32. Optical resolution and determination of the absolute configuration of compound $\mathbf{1 0 .}$

S33. Optical resolution and determination of the absolute configuration of compound $\mathbf{1 1 .}$

S34. Optical resolution and determination of the absolute configuration of compound $\mathbf{1 3 .}$

S35. Optical resolution and determination of the absolute configuration of compound 22.

S36. Optical resolution and determination of the absolute configuration of compound 25.

S37. Optical resolution and determination of the absolute configuration of compound $\mathbf{3 3}$.

S38. Optical resolution and determination of the absolute configuration of compound $\mathbf{3 4}$.

S39. The experimental ECD spectra of compounds 3 and 4 . 
S1. Chemical structure of bletillatin A (1).

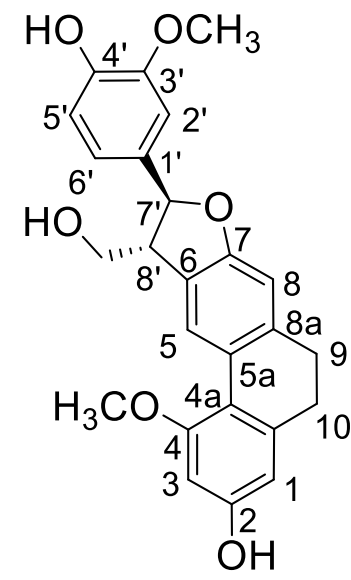

S2. ${ }^{1} \mathrm{H}$ NMR $\left(600 \mathrm{MHz}\right.$, methanol- $\left.d_{4}\right)$ spectrum of bletillatin A (1).

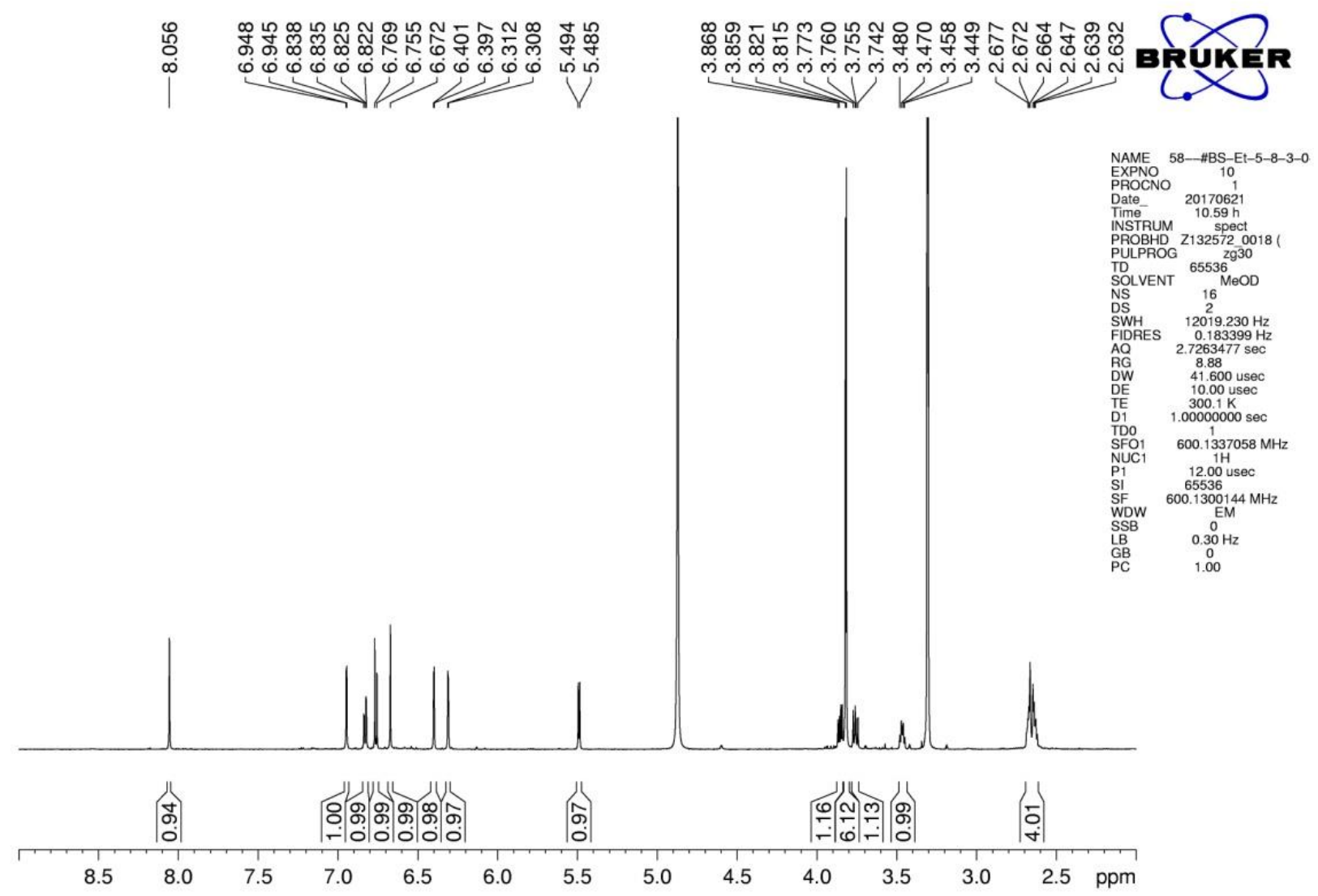


S3. ${ }^{13} \mathrm{C}$ NMR $\left(150 \mathrm{MHz}\right.$, methanol- $\left.d_{4}\right)$ spectrum of bletillatin A (1).

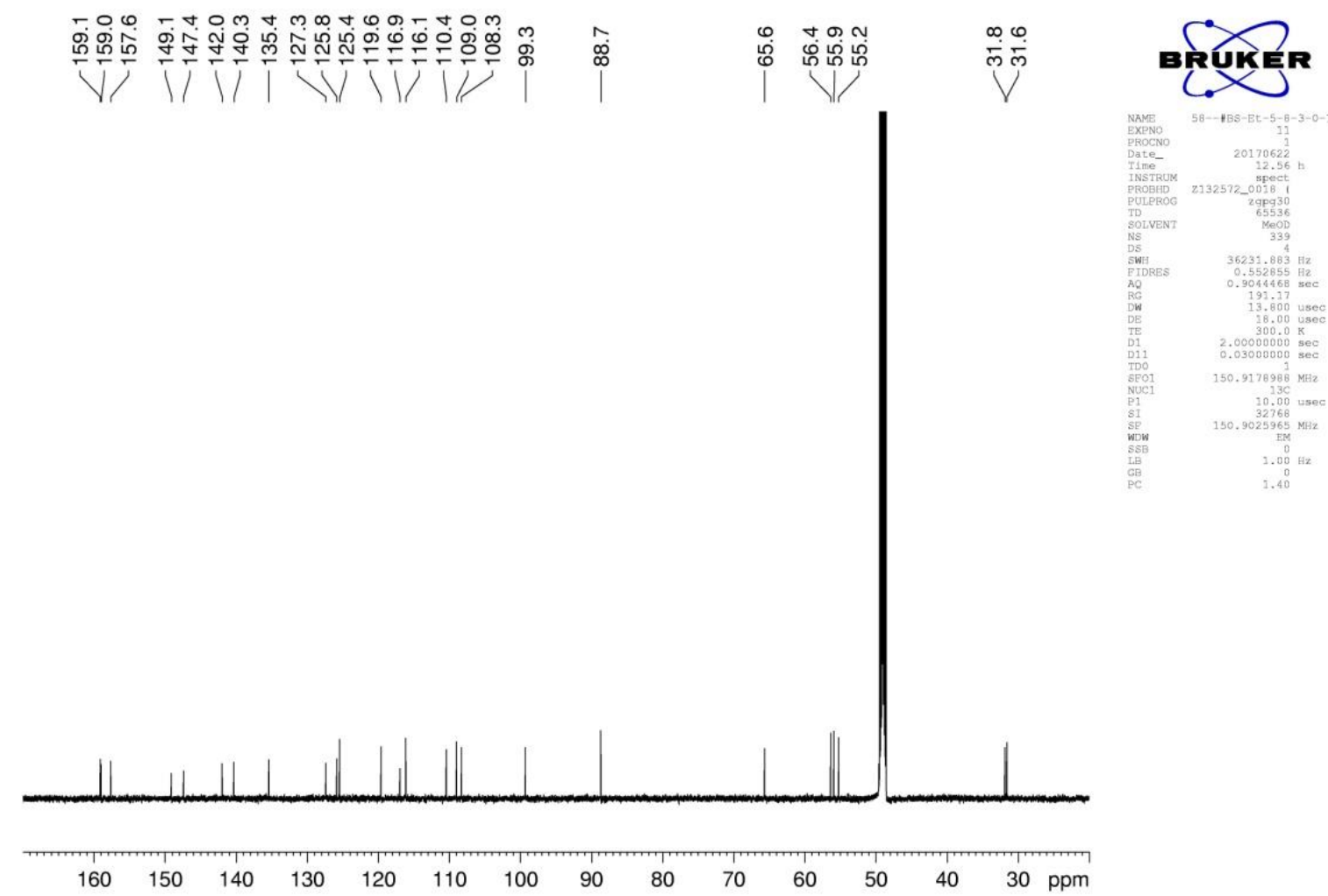

S4. HSQC spectrum of bletillatin A (1).
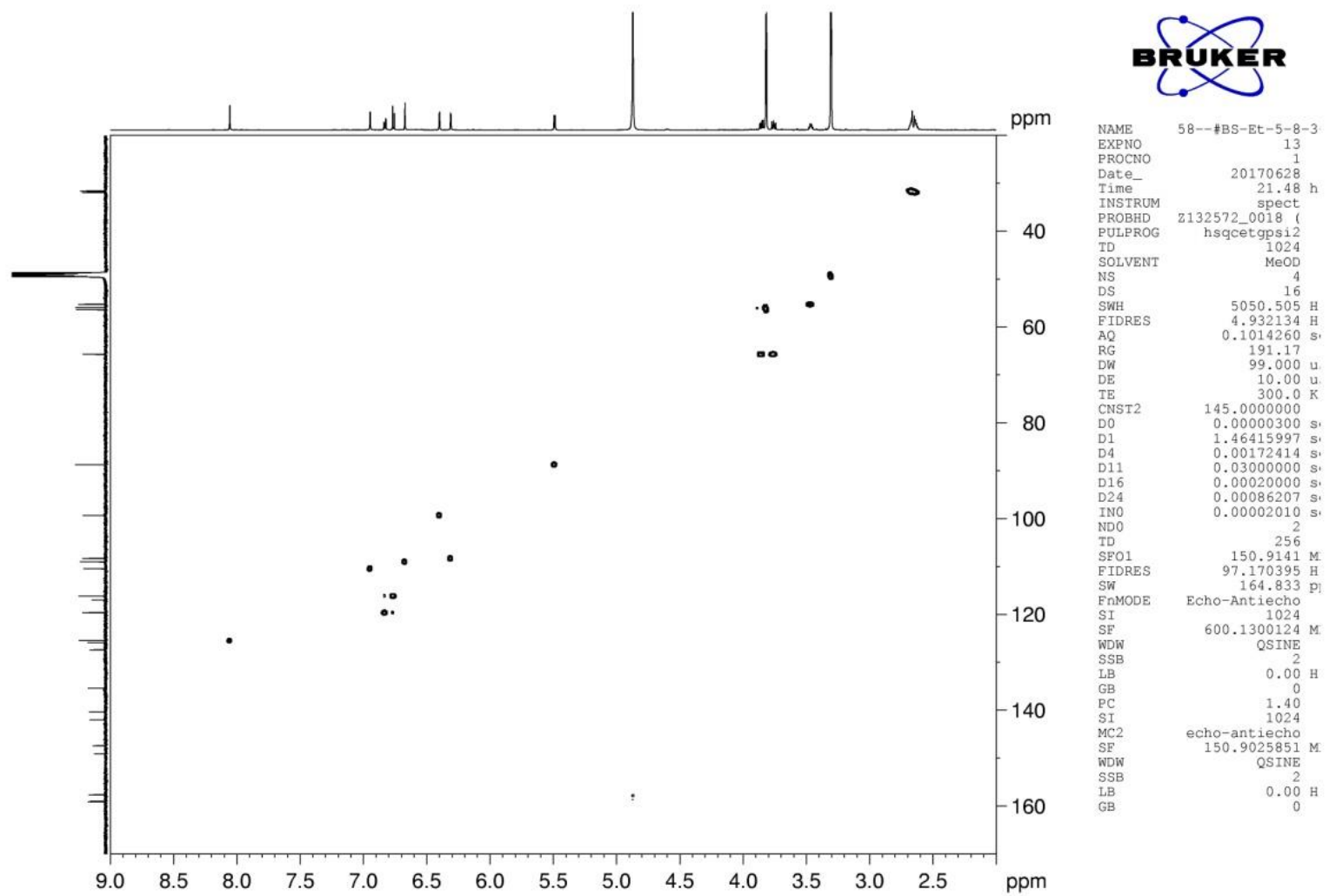
S5. HMBC spectrum of bletillatin A (1).

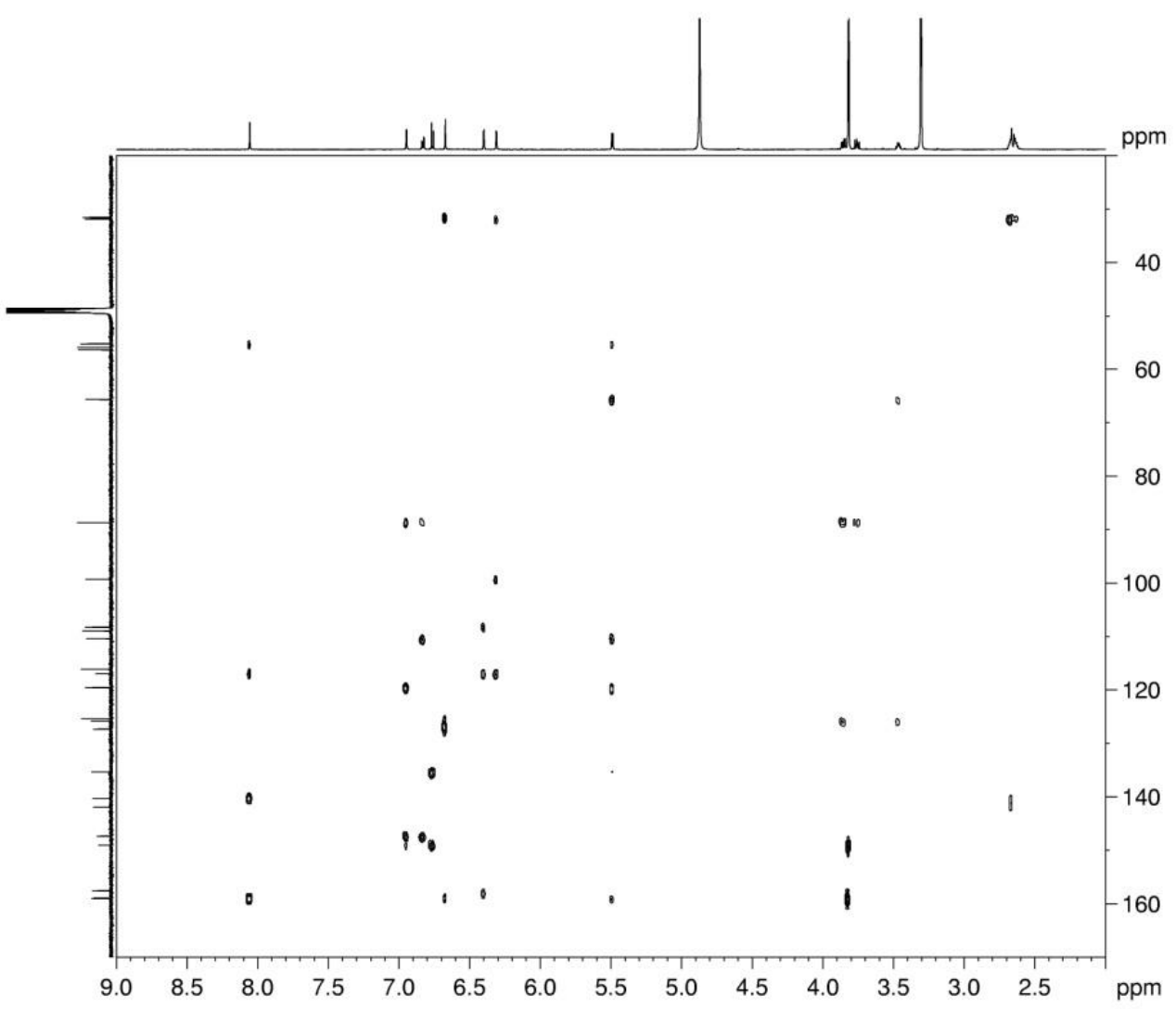

\section{BRUK}

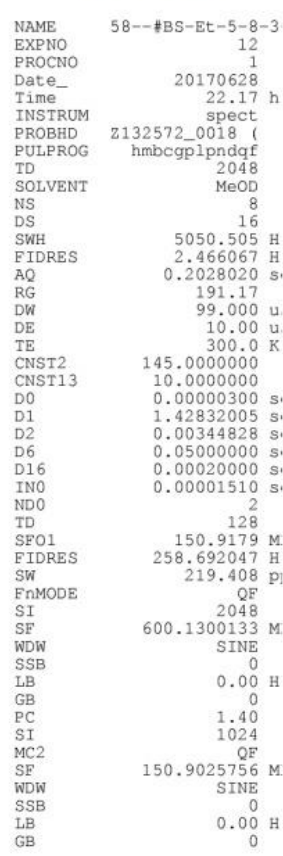

S6. NOESY spectrum of bletillatin A (1).
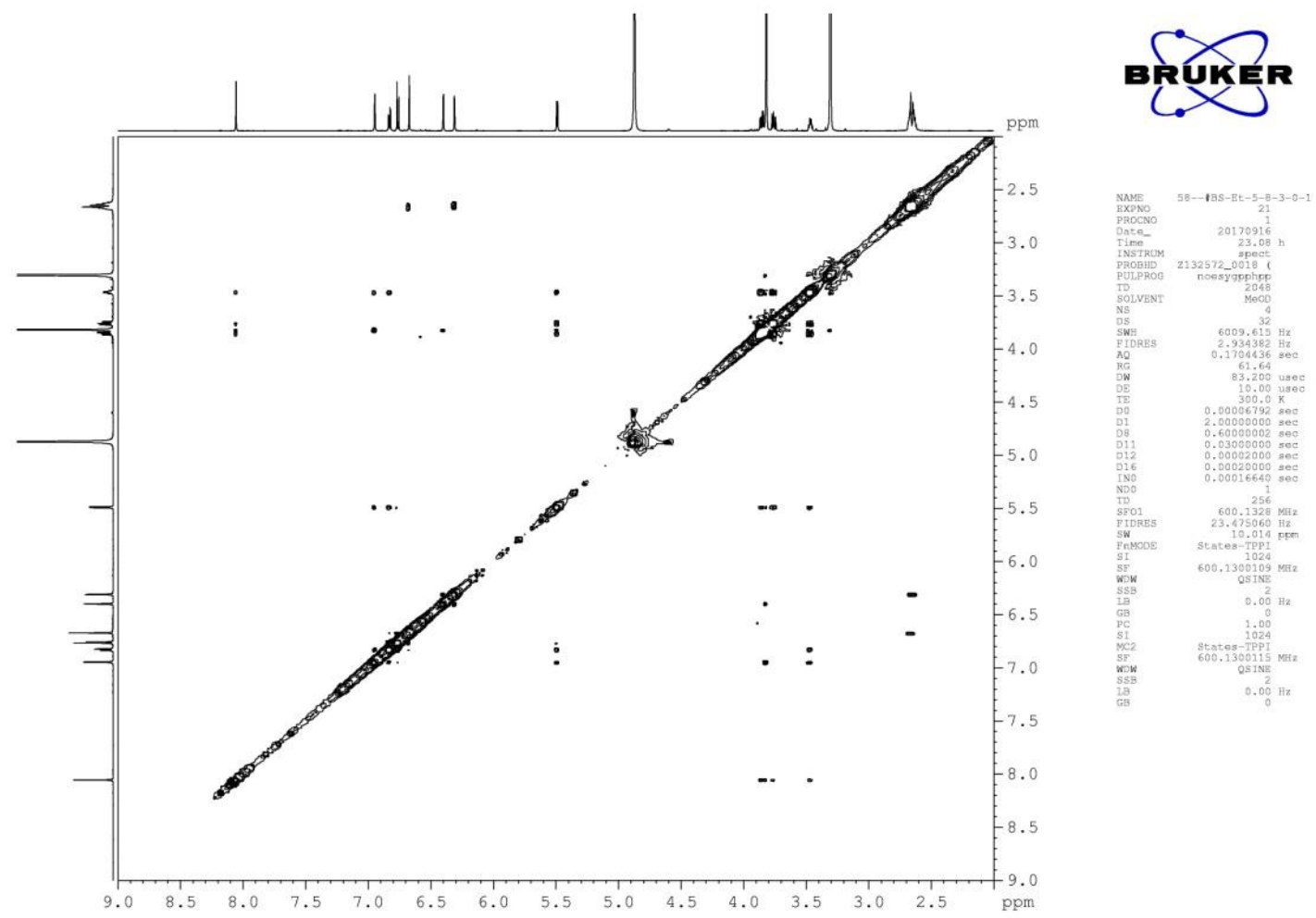
S7. HRESIMS spectrum of bletillatin A (1).

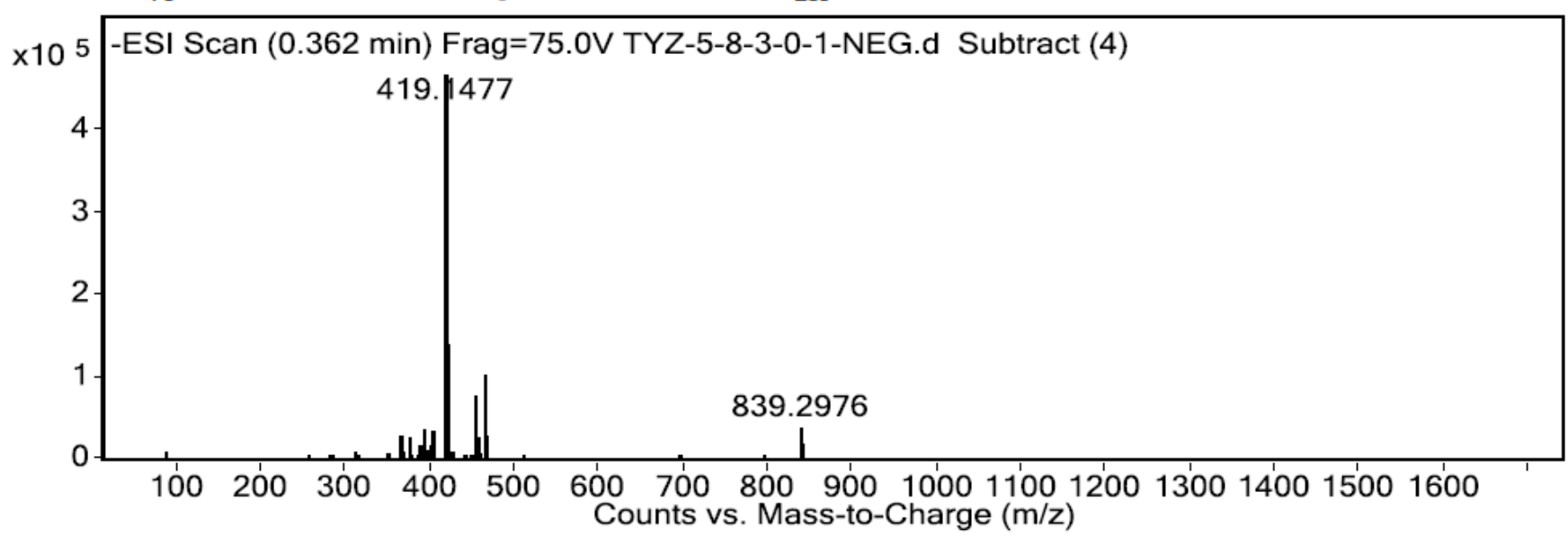


S8. Chemical structure of bletillatin B (2).

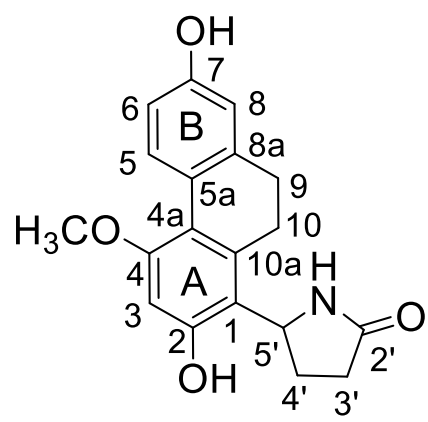

S9. ${ }^{1} \mathrm{H}$ NMR $\left(600 \mathrm{MHz}\right.$, methanol- $\left.d_{4}\right)$ spectrum of bletillatin B (2).

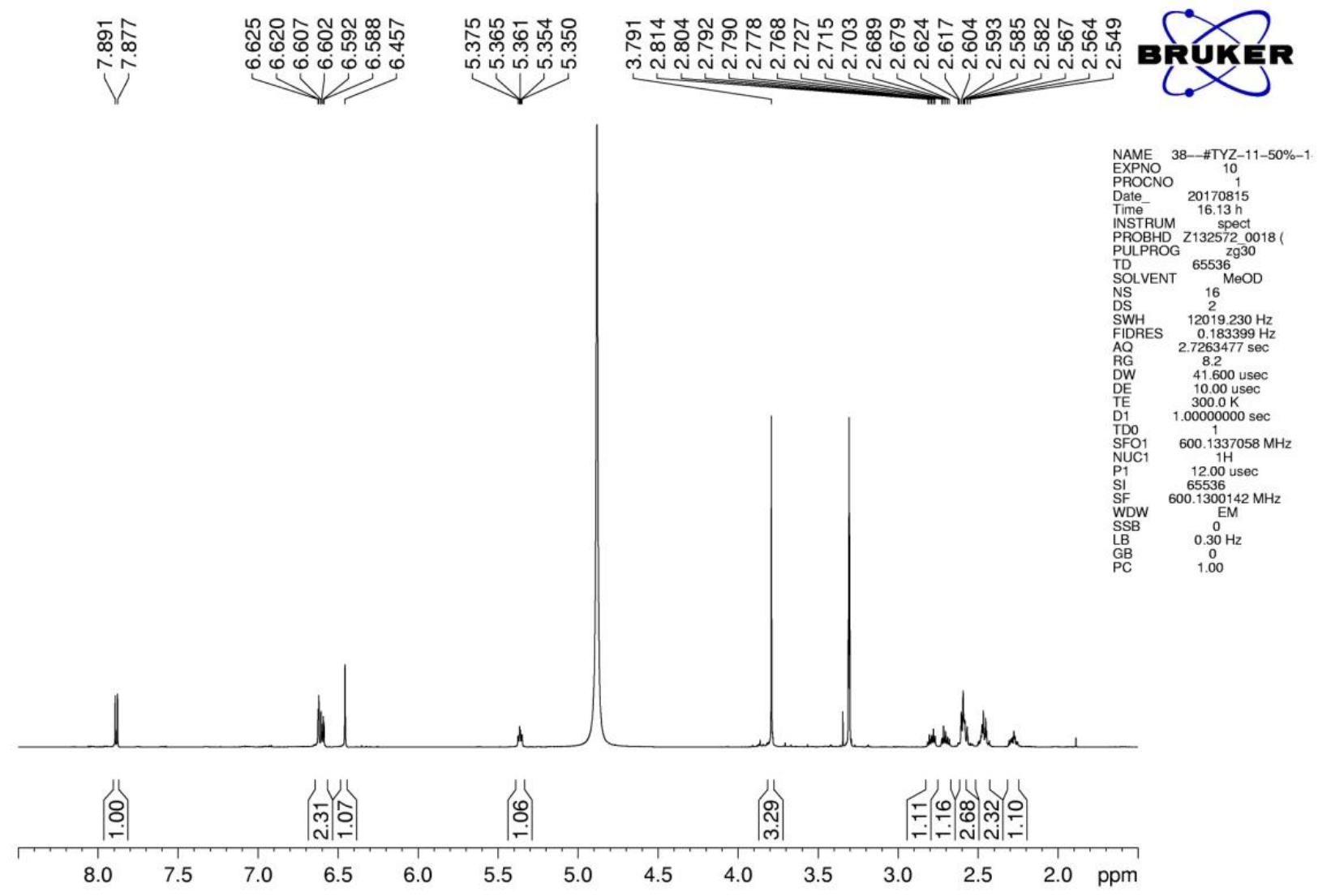


S10. ${ }^{13} \mathrm{C}$ NMR $\left(150 \mathrm{MHz}\right.$, methanol- $\left.d_{4}\right)$ spectrum of bletillatin B (2).

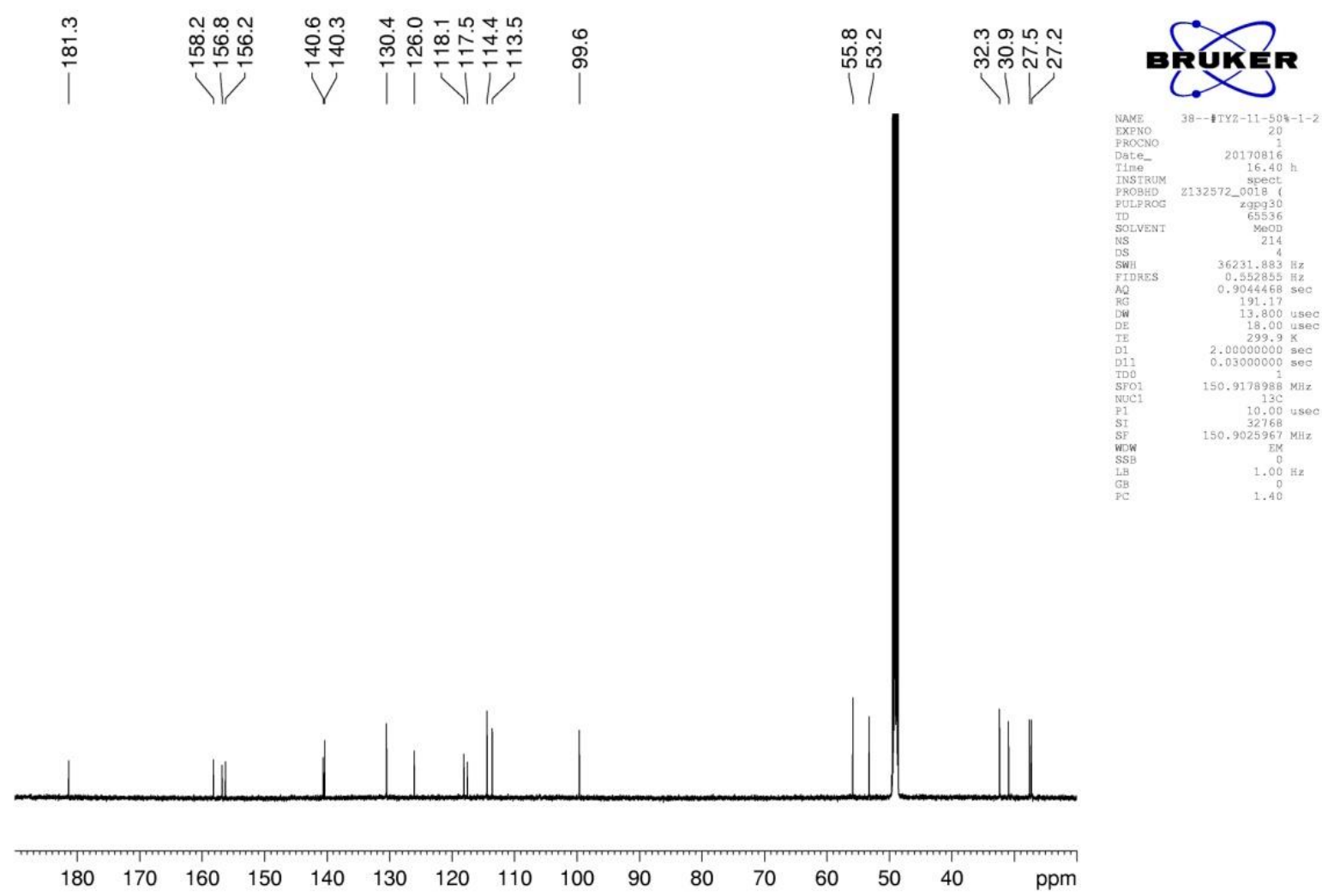

S11. HSQC spectrum of bletillatin B (2).
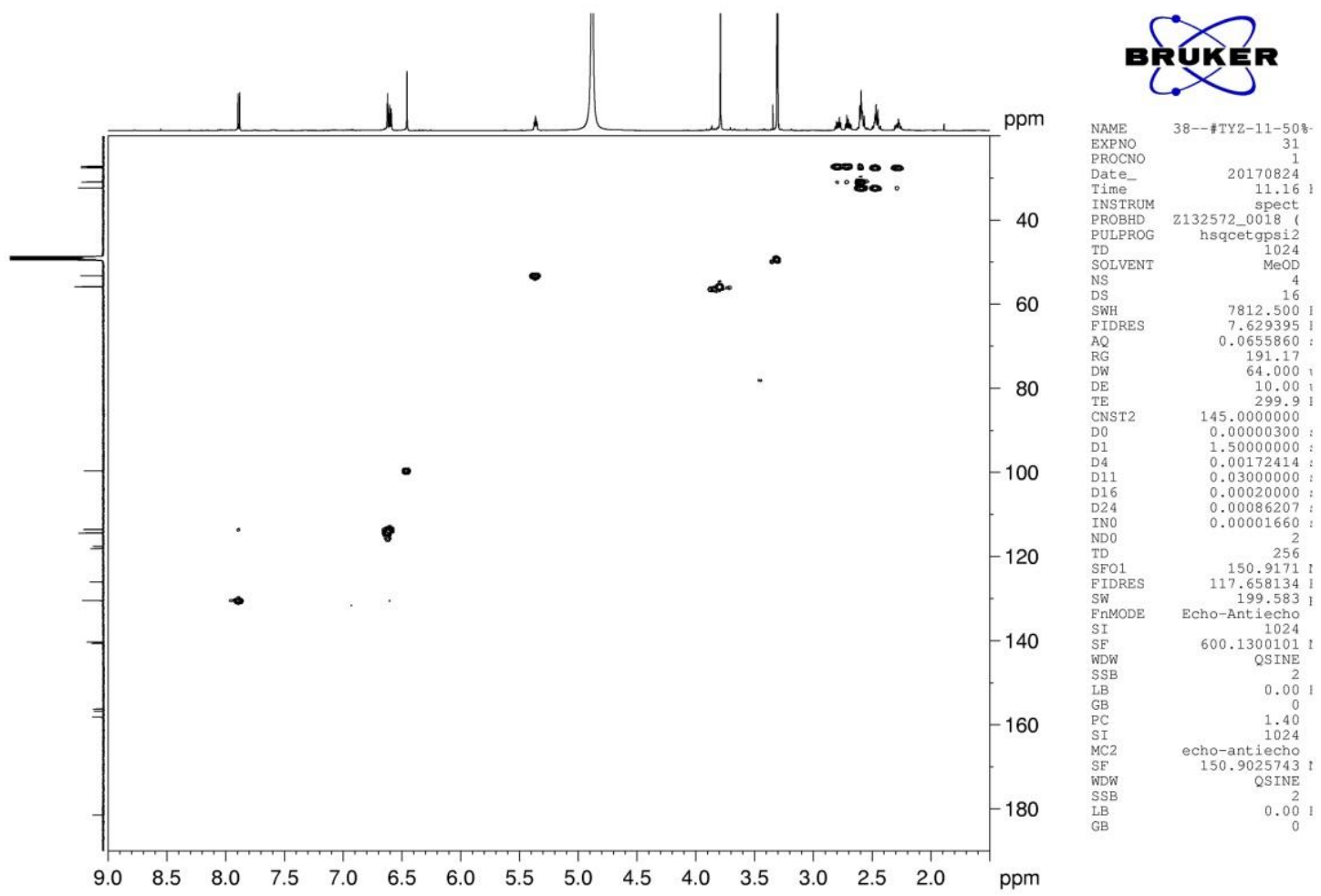
S12. HMBC spectrum of bletillatin B (2).

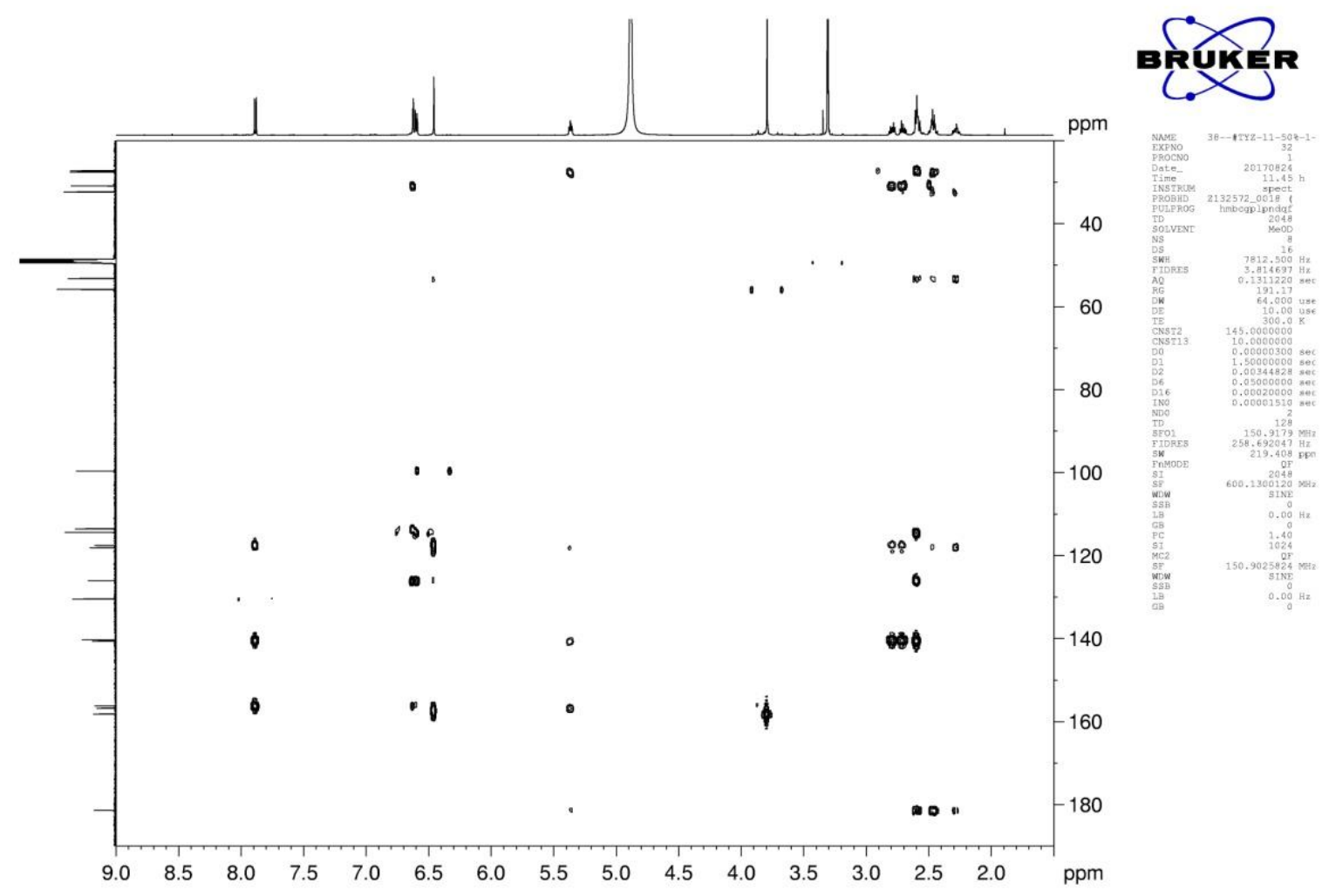

S13. NOESY spectrum of bletillatin B (2).
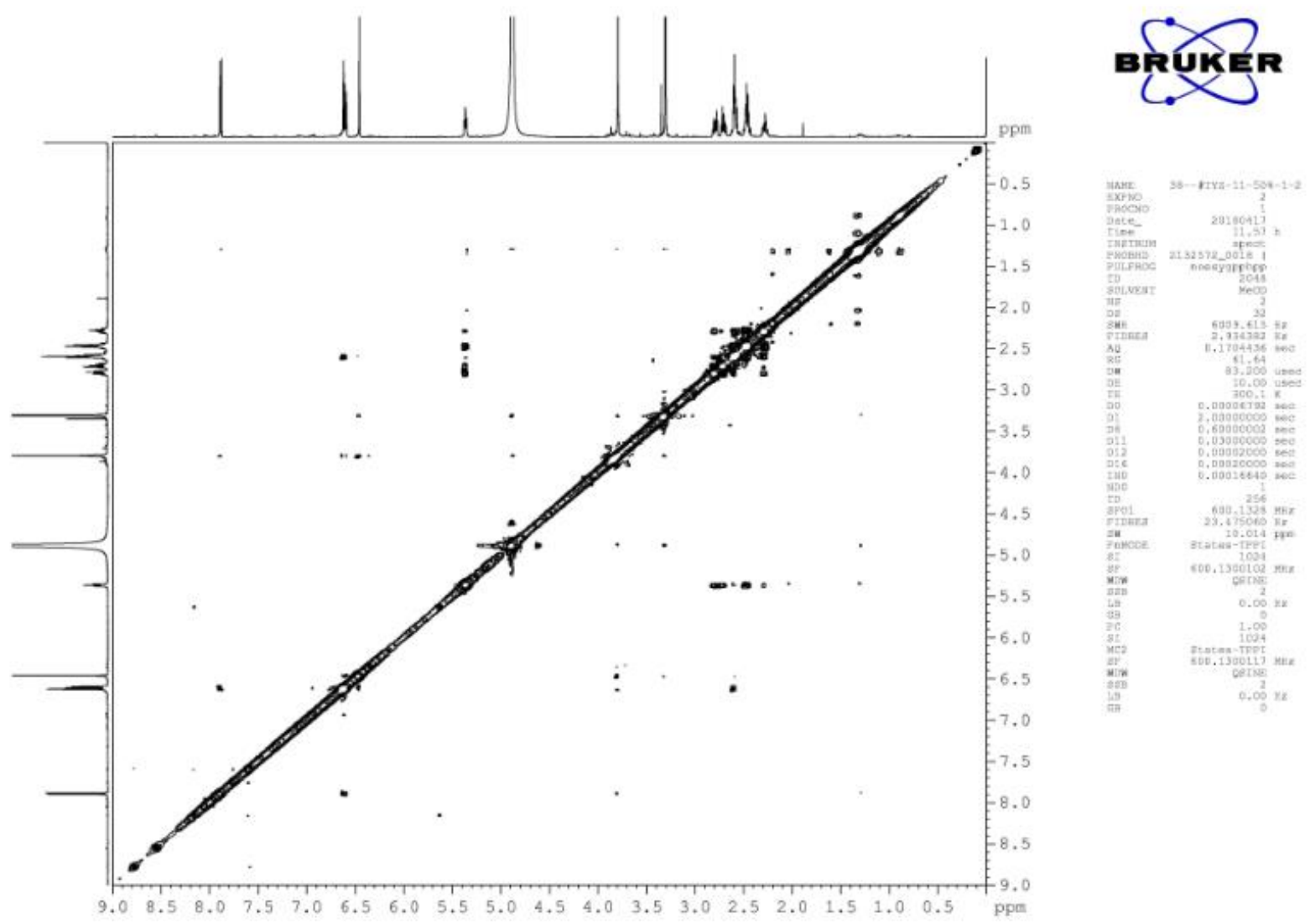
S14. HRESIMS spectrum of bletillatin B (2).

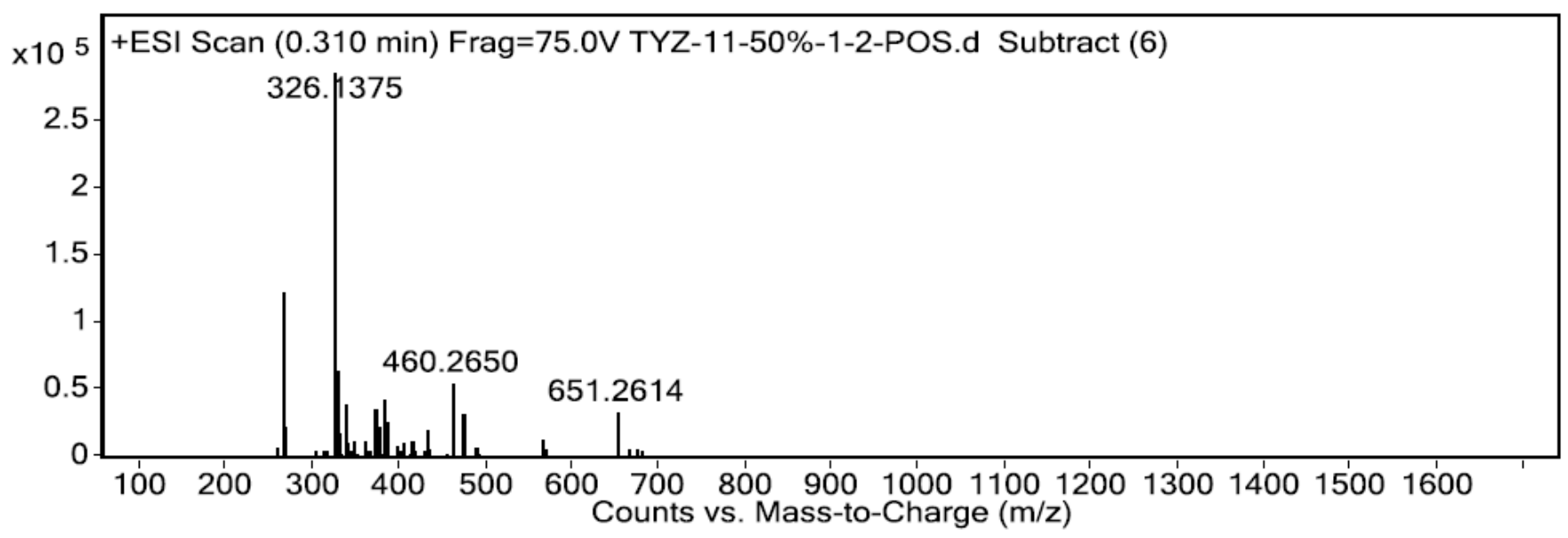


S15. Chemical structure of bletillatin C (3).

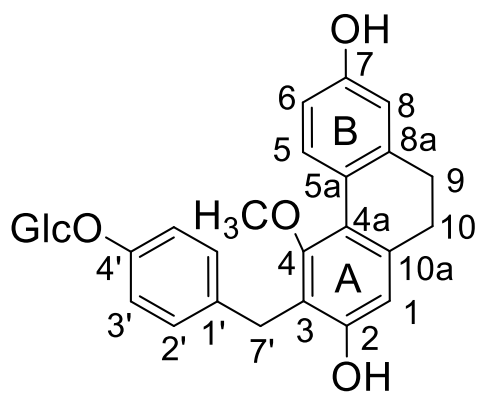

S16. ${ }^{1} \mathrm{H}$ NMR (600MHz, methanol- $\left.d_{4}\right)$ spectrum of bletillatin C (3).

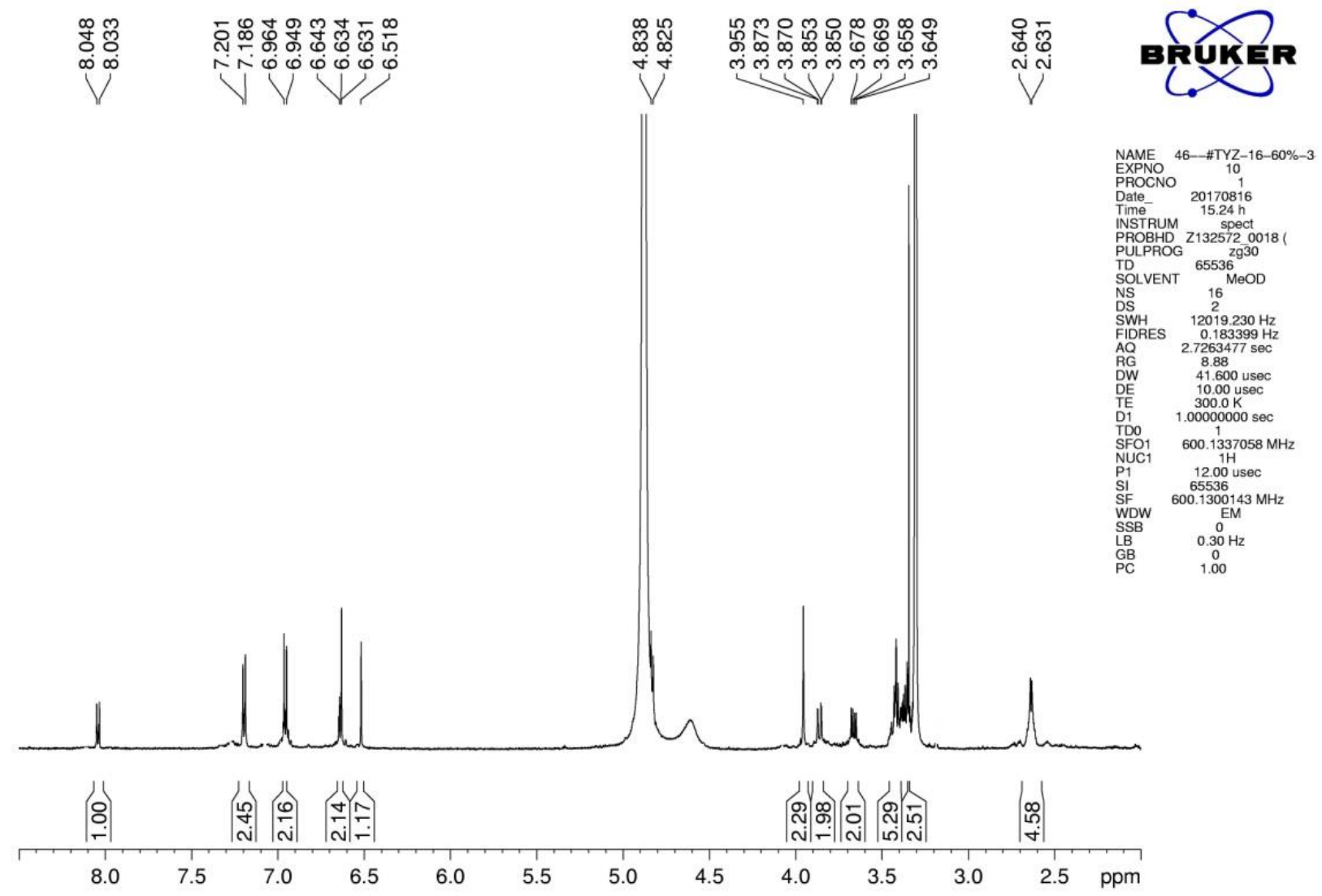


S17. ${ }^{13} \mathrm{C}$ NMR $\left(150 \mathrm{MHz}\right.$, methanol- $\left.d_{4}\right)$ spectrum of bletillatin C (3).

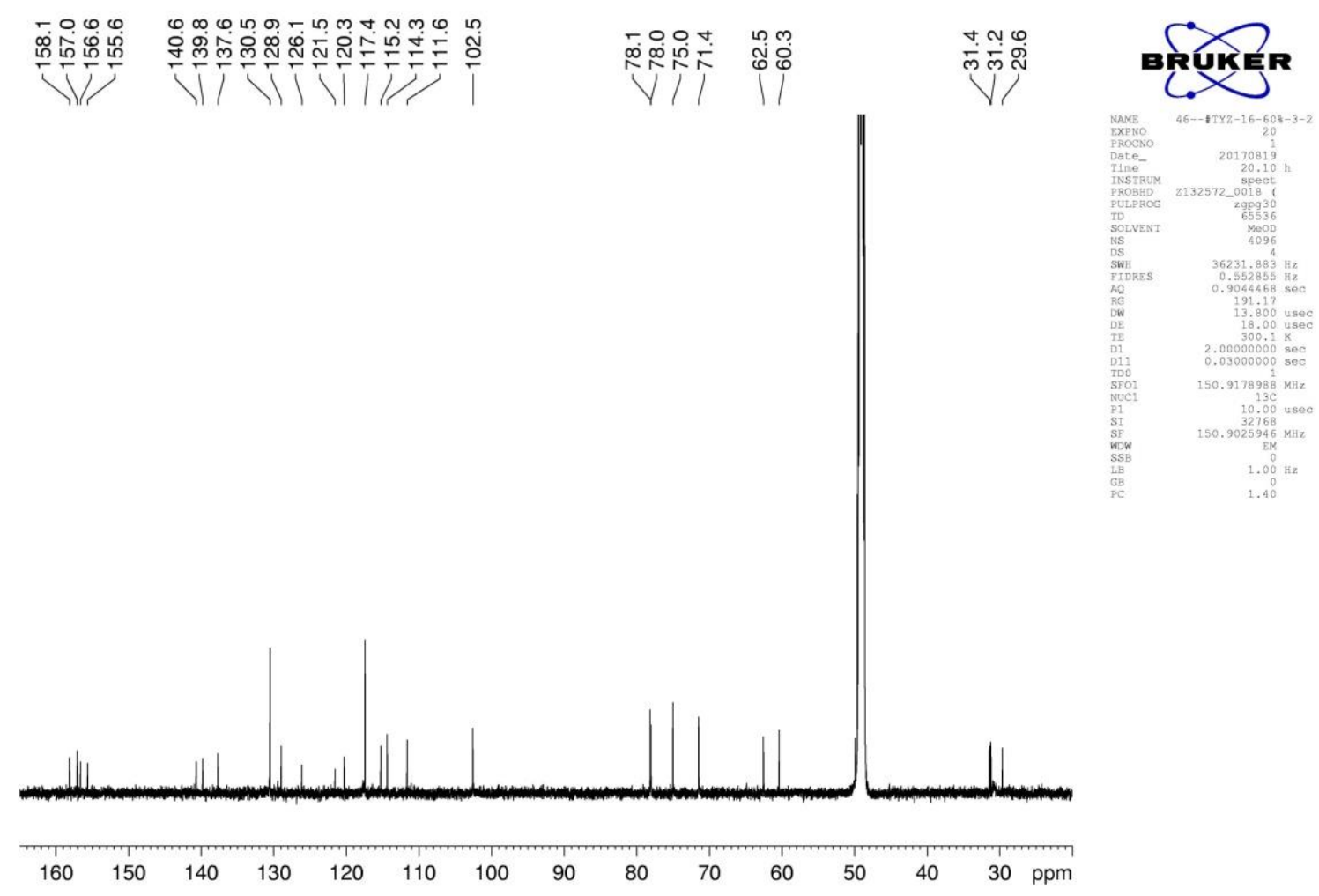

S18. HSQC spectrum of bletillatin C (3).
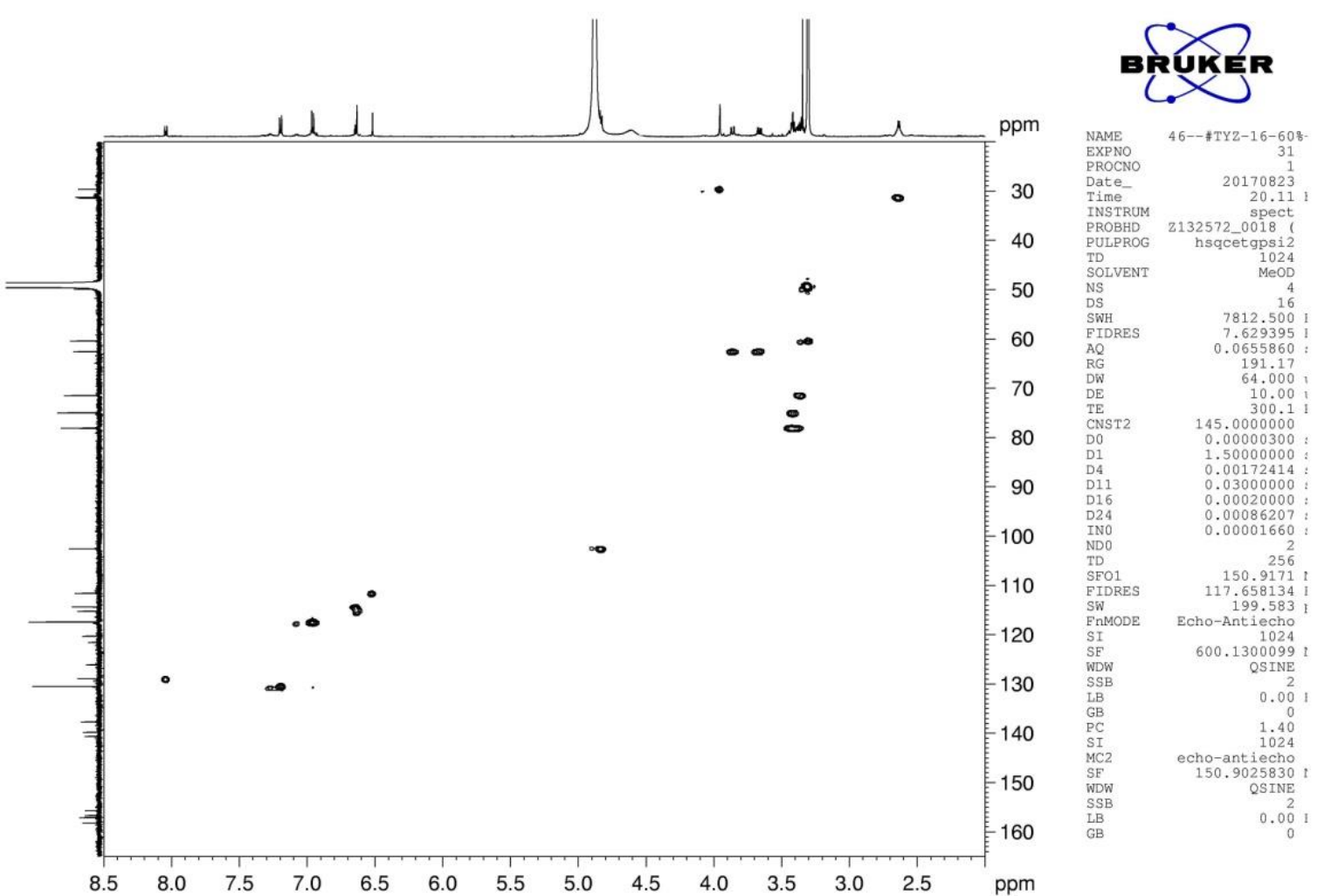
S19. HMBC spectrum of bletillatin C (3).

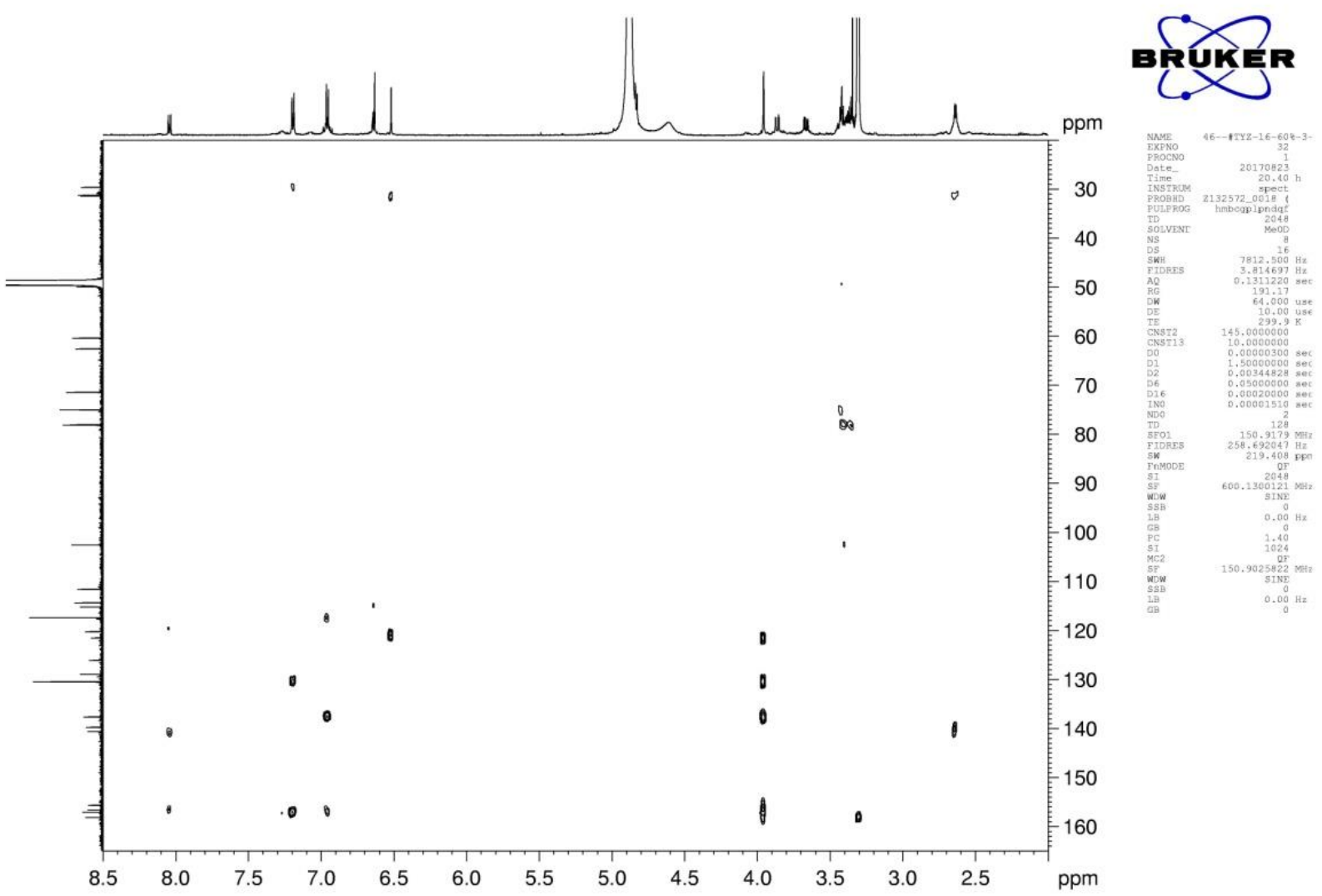

S20. HRESIMS spectrum of bletillatin C (3).

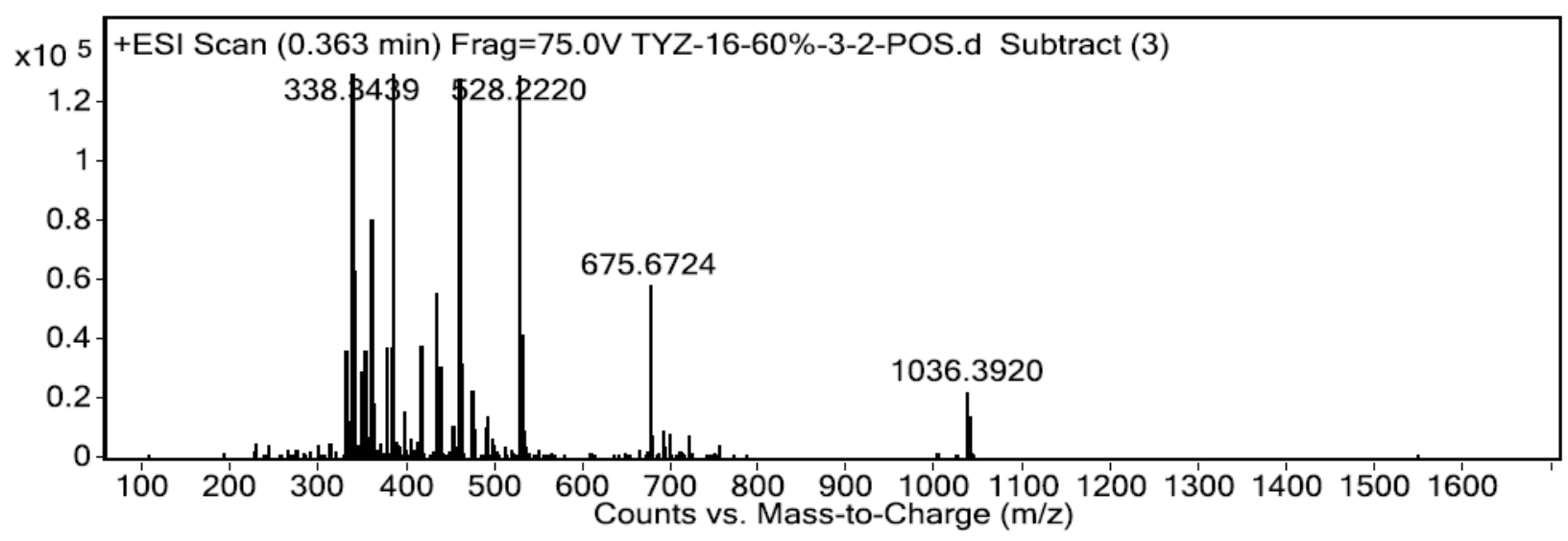


S21. Chemical structure of bletillatin D (4).

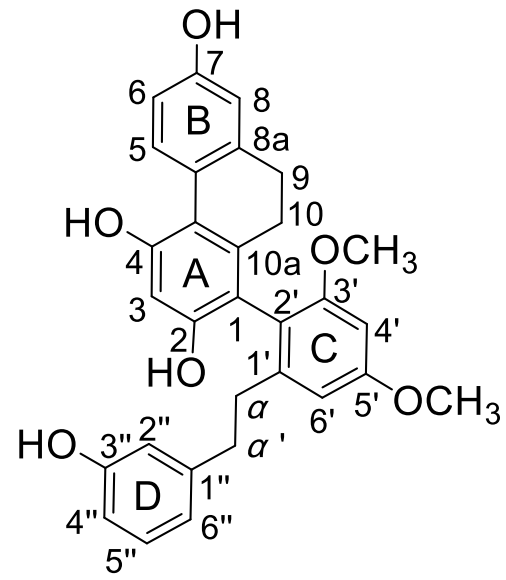

S22. ${ }^{1} \mathrm{H}$ NMR $\left(600 \mathrm{MHz}\right.$, methanol- $\left.d_{4}\right)$ spectrum of bletillatin D (4).

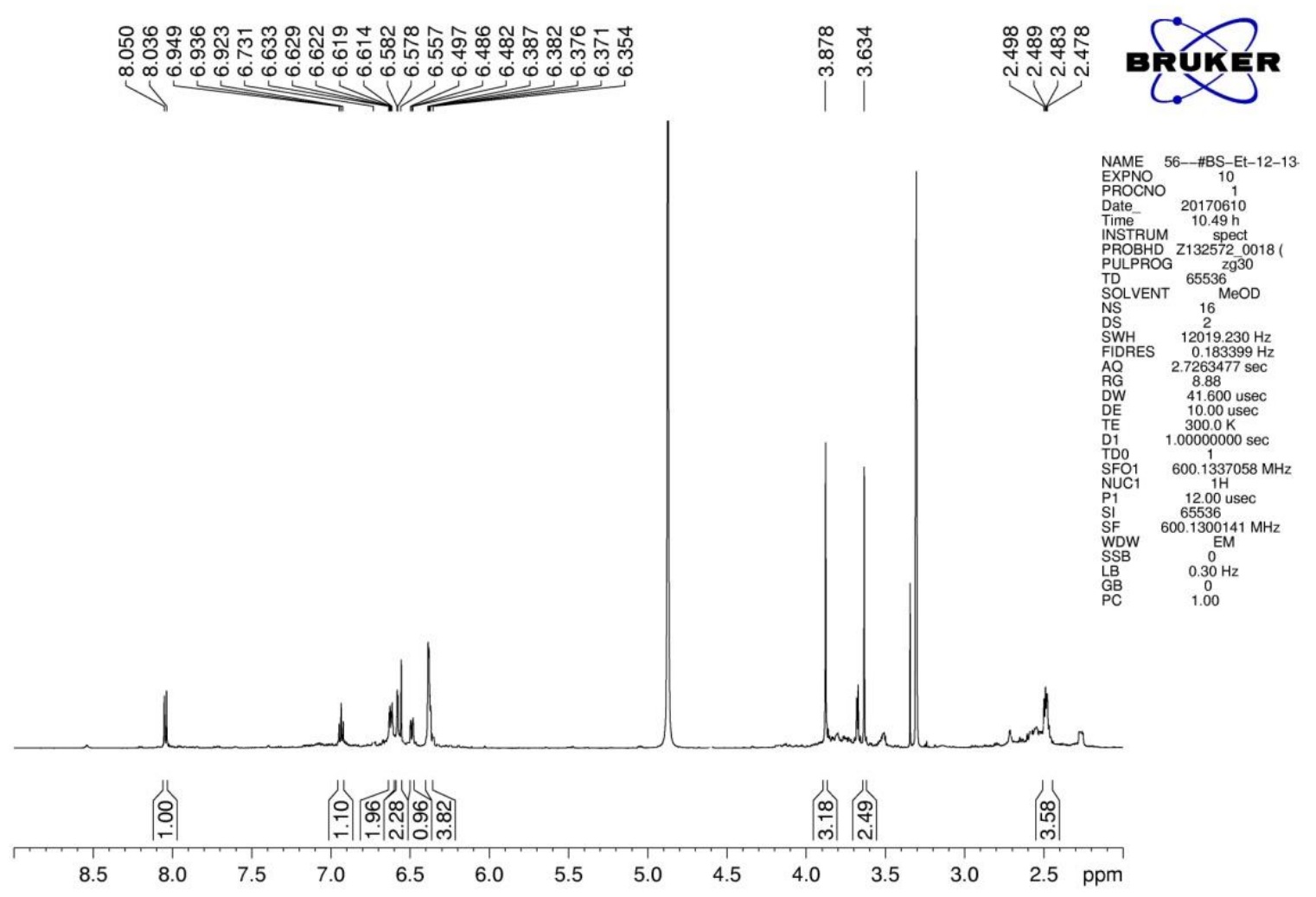


S23. ${ }^{13} \mathrm{C}$ NMR (150MHz, methanol- $\left.d_{4}\right)$ spectrum of bletillatin D (4).
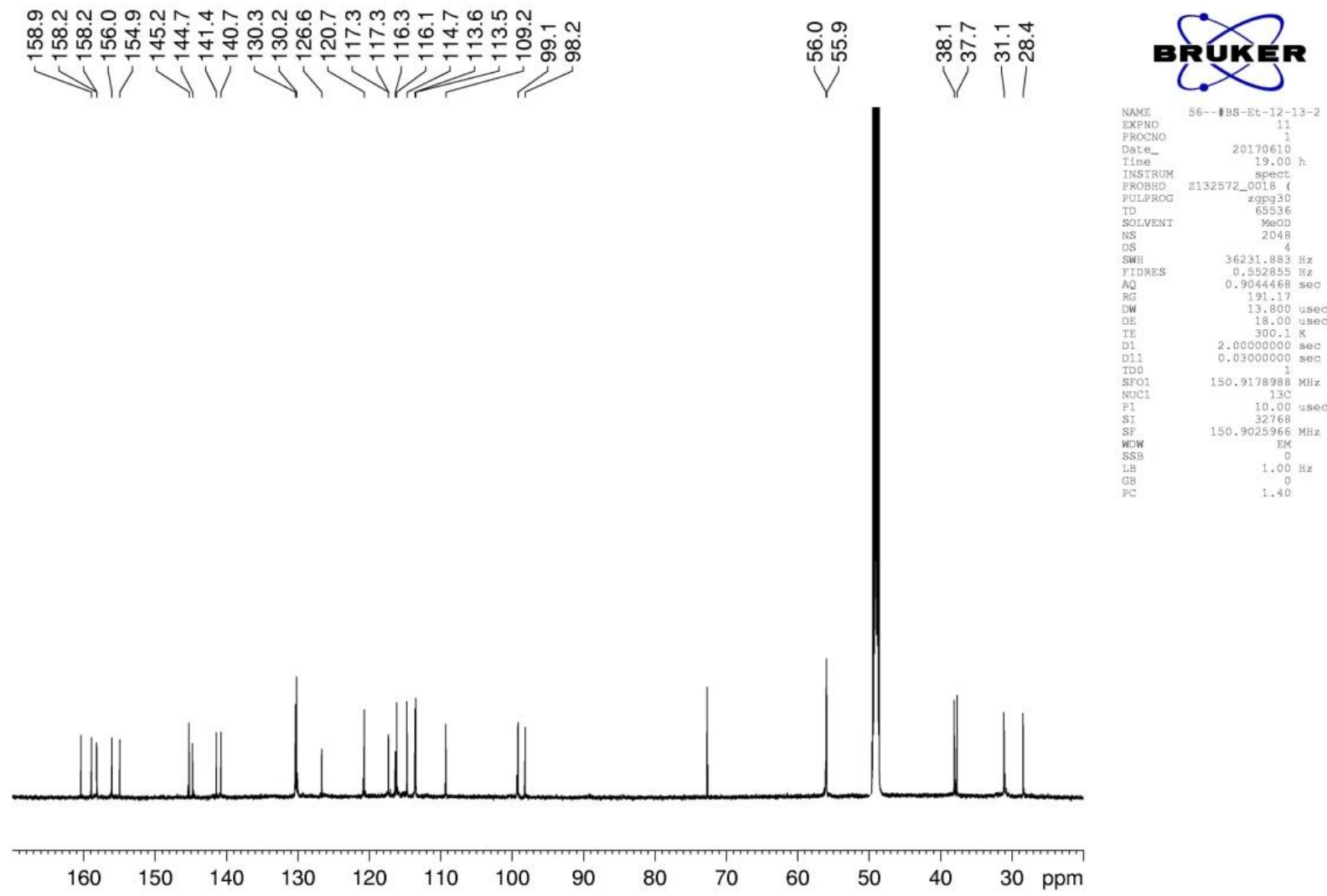

S24. HSQC spectrum of bletillatin D (4).

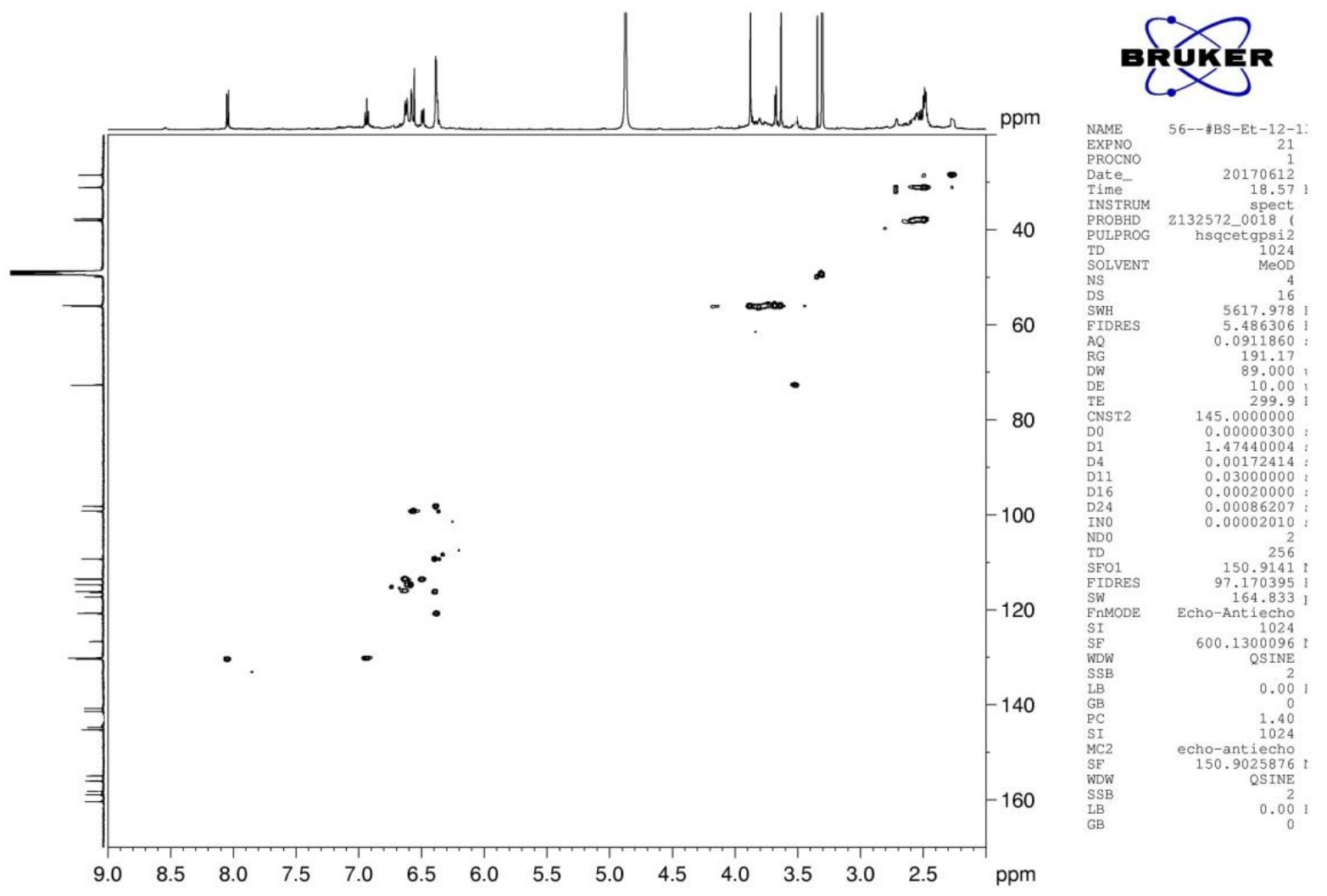


S25. HMBC spectrum of bletillatin D (4).

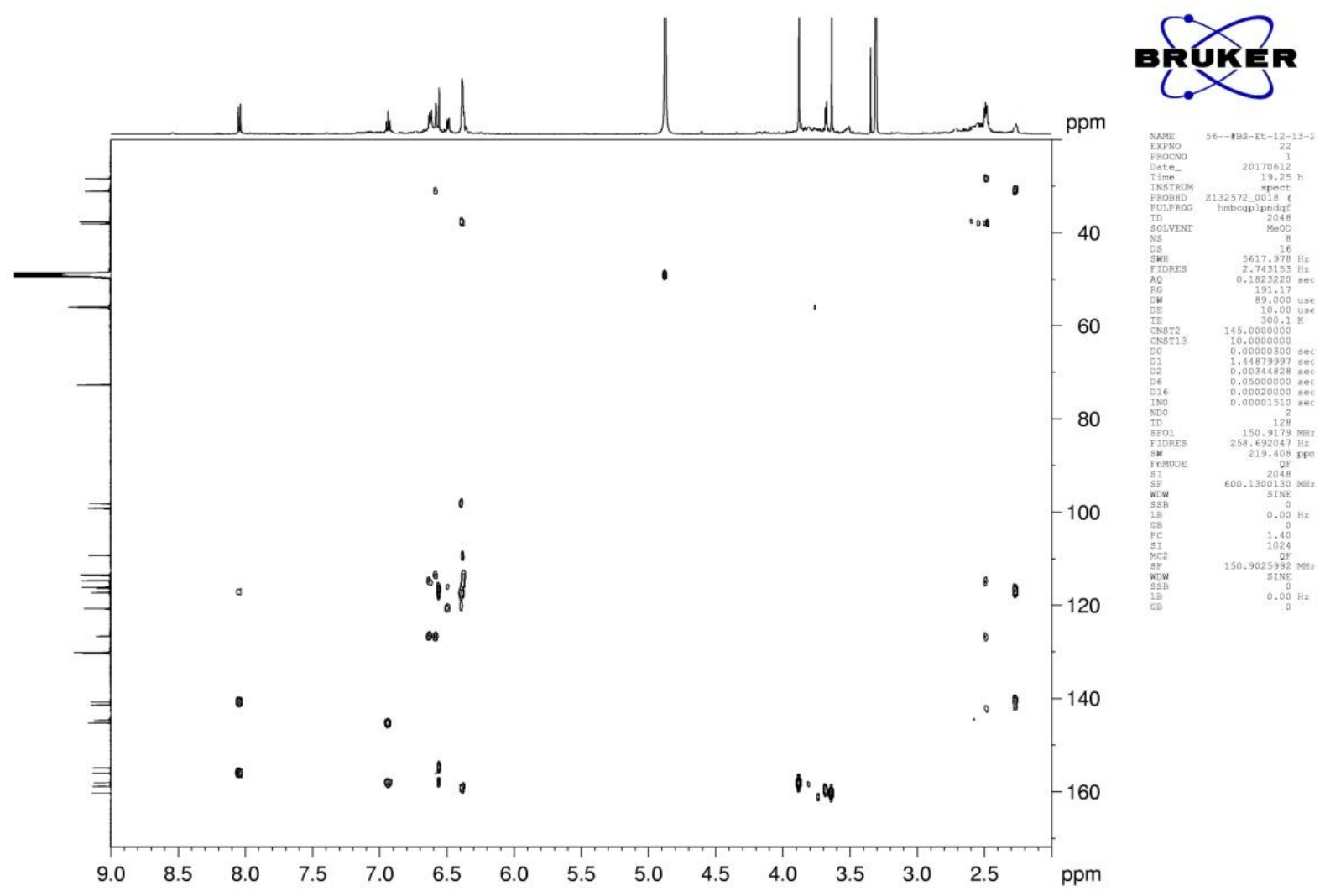

S26. HRESIMS spectrum of bletillatin D (4).

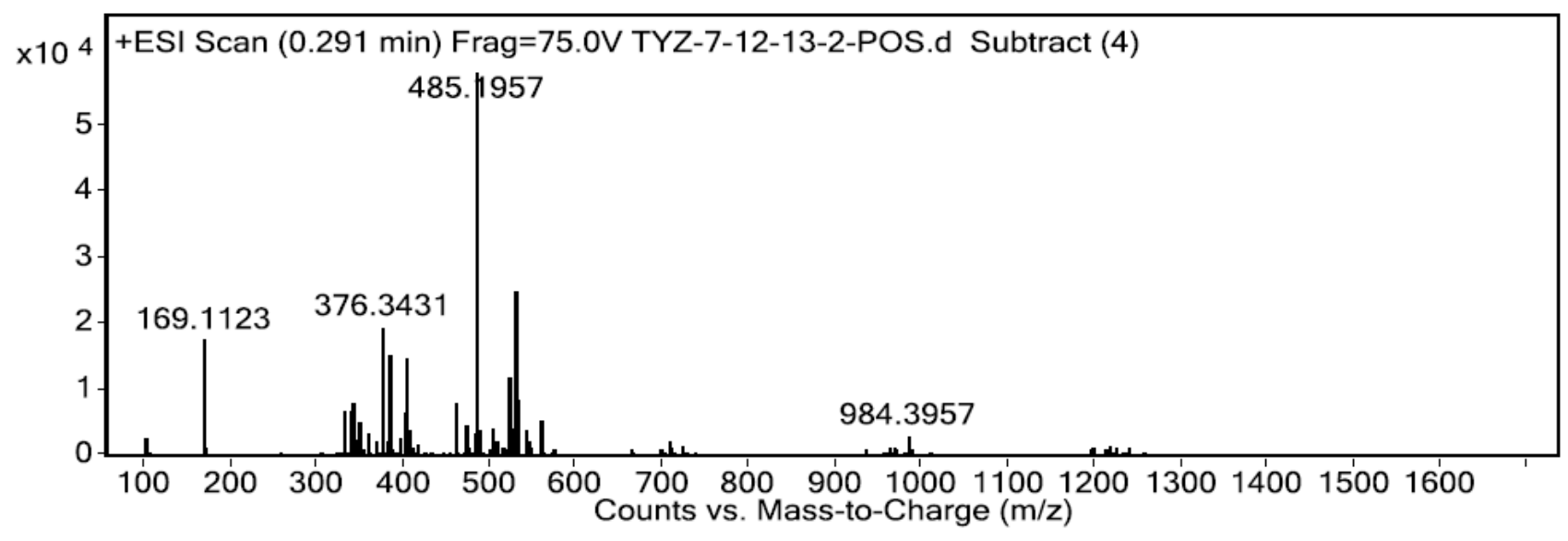


S27. Acid hydrolysis of compound $\mathbf{3}$ and HPLC analysis for sugar residues. (A: standard sugar; B: sugar residue of compound $\mathbf{3}$ )

A:

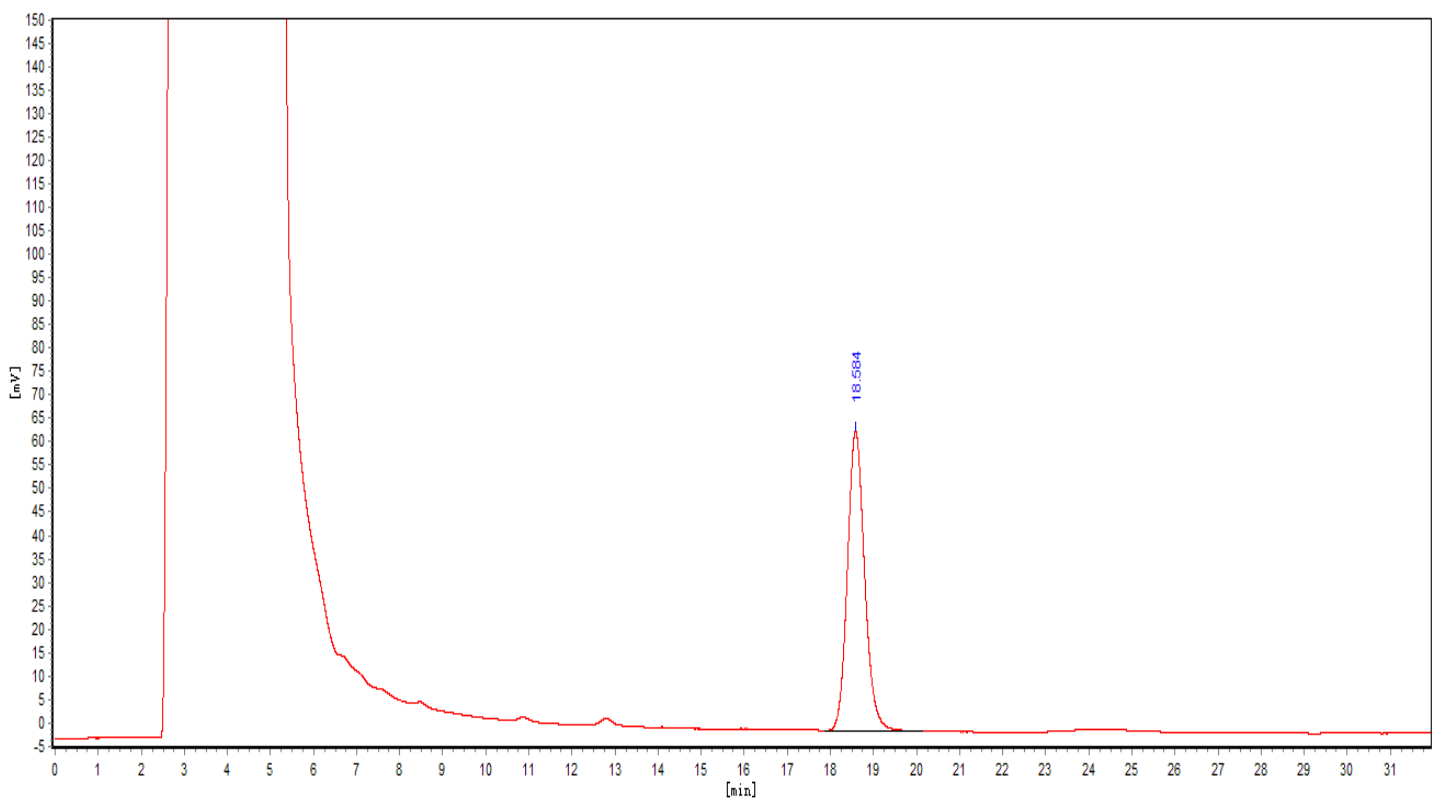

B:

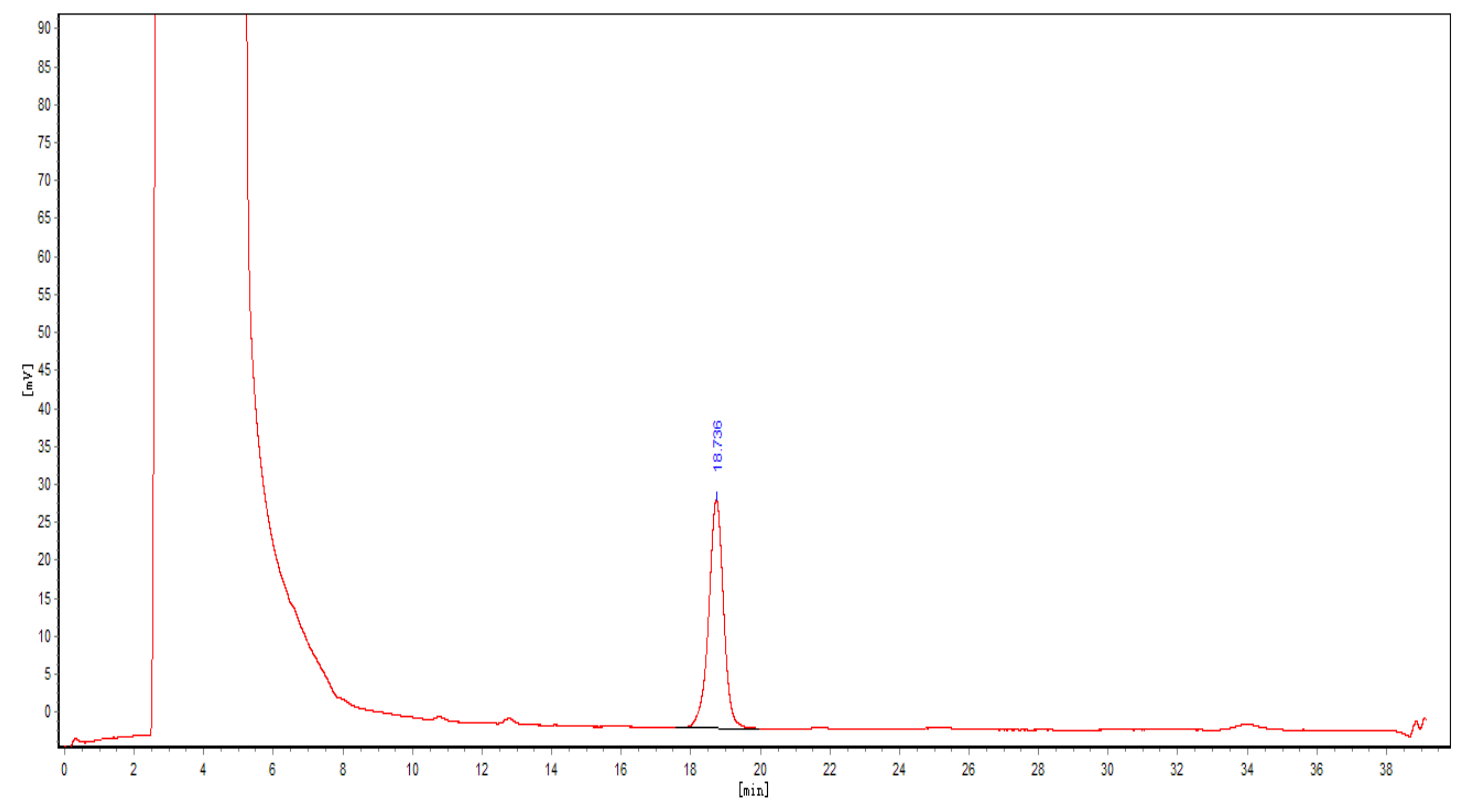


S28. The experimental method used for ECD calculations of compounds $\mathbf{1}, \mathbf{2}$, and $\mathbf{2 2}$.

All structures were established by Schrodinger 2013 package. Conformational searches were performed using the bioactive search function of conformational search protocol of the Schrodinger 2013 package with 50 target conformers. The conformers generated from conformational search were optimized at the B3LYP/631G (d) level using Gaussian09 package. The optimized conformers were aligned using the flexible ligand alignment protocol to examine if there were identical conformers for some structurally similar conformers would lead to the totally identical conformer after structure optimization. After merging the identical conformers, the remaining conformers were subjected to frequent analysis at the B3LYP/6-31G (d) level and the population of each conformer was determined based on Boltzmann distribution. ECD computations for all conformers were carried out at the B3LYP/6-31G (d) level in the gas phase. The calculated ECD spectrums were visualized and Boltzmann averaged using specdis software. ${ }^{\text {S1-S3 }}$

Selected structures and population of the low-energy B3LYP/6-31G (d) in vacuo conformers of (aS,7'S,8'R)-1 based on experimental NOE correlations.
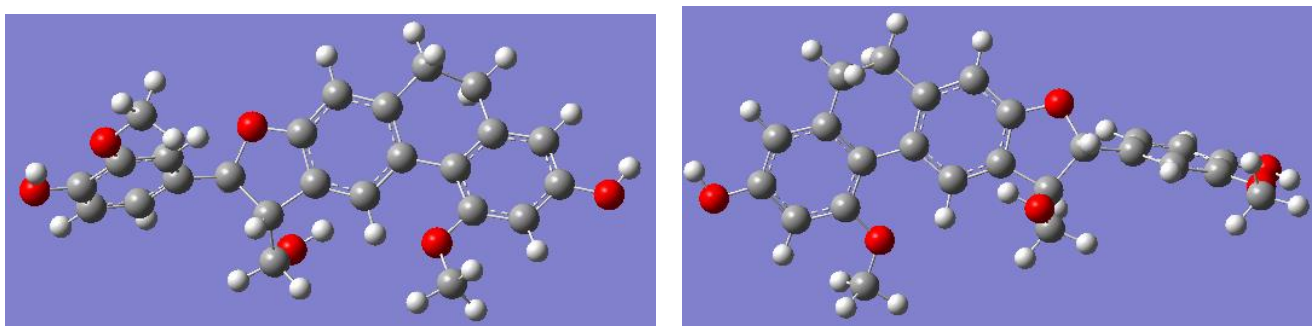

\section{$\mathrm{A}: 41.55 \%$}

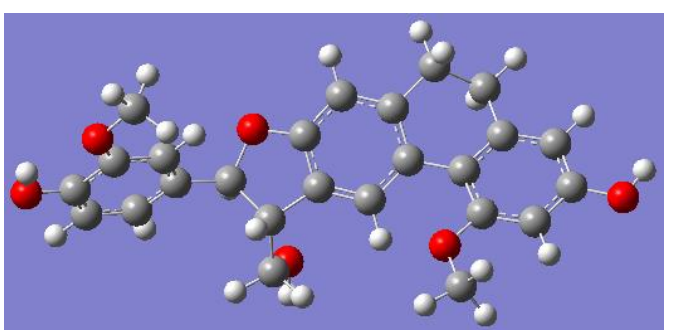

B: $23.04 \%$

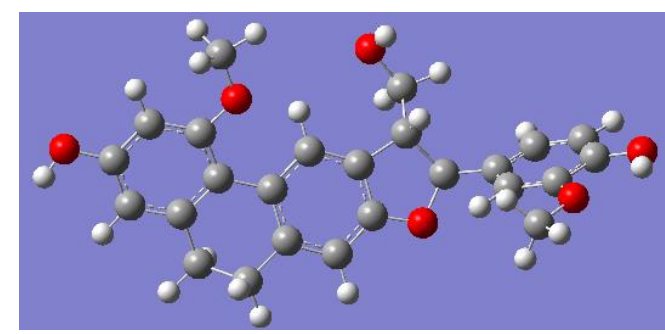

C: $9.48 \%$

D: $7.22 \%$

Selected structures and population of the low-energy B3LYP/6-31G (d) in vacuo conformers of (aR,7'R,8'S)1 based on experimental NOE correlations.

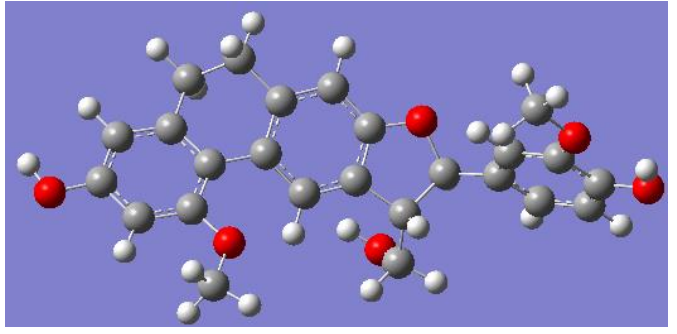

A: $41.55 \%$

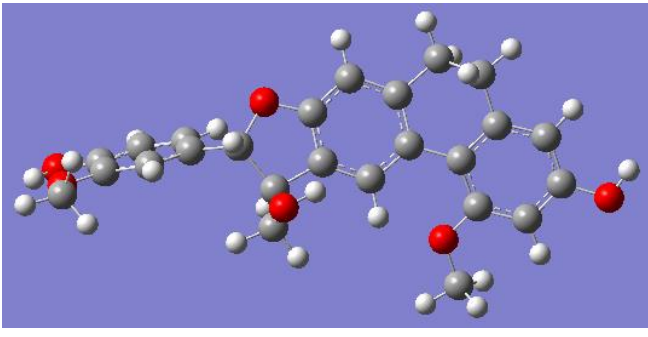

B: $23.04 \%$ 


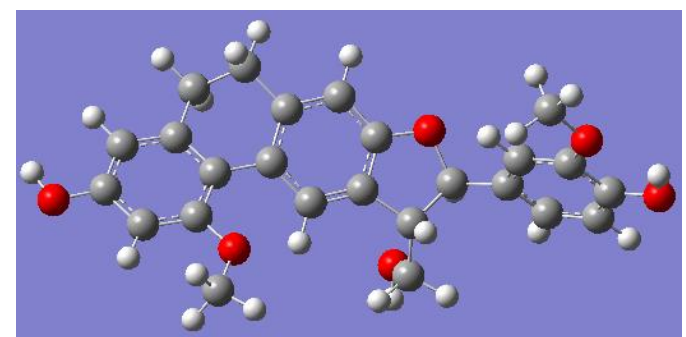

C: $9.48 \%$

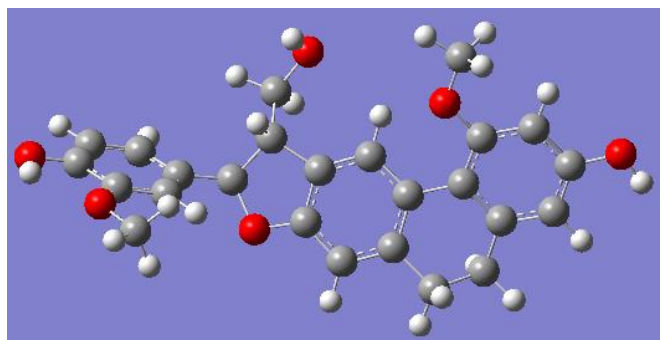

D: $7.22 \%$

Selected structures and population of the low-energy B3LYP/6-31G (d) in vacuo conformers of (aR,5'S)-2 based on experimental NOE correlations.
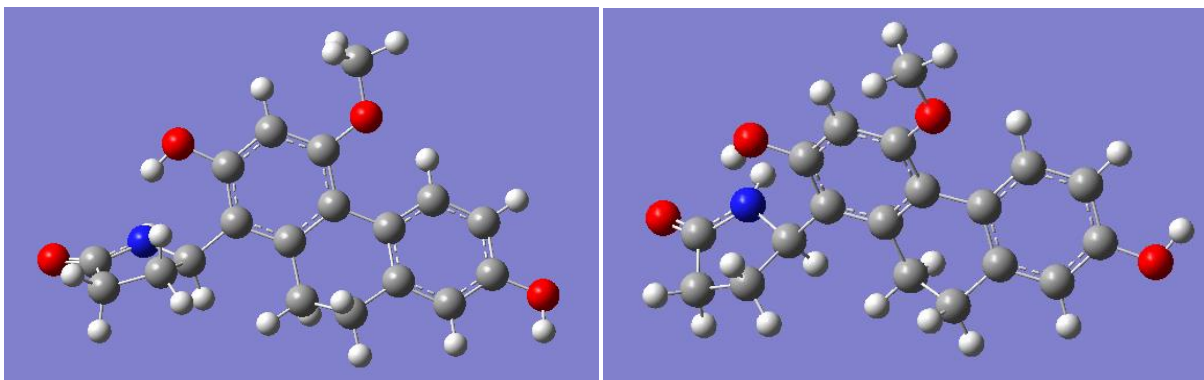

A: $33.49 \%$

B: $31.26 \%$

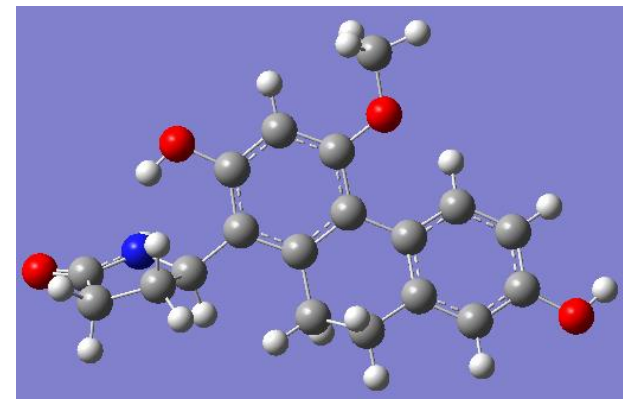

C: $33.49 \%$

Selected structures and population of the low-energy B3LYP/6-31G (d) in vacuo conformers of (aS,5'R)-2 based on experimental NOE correlations.
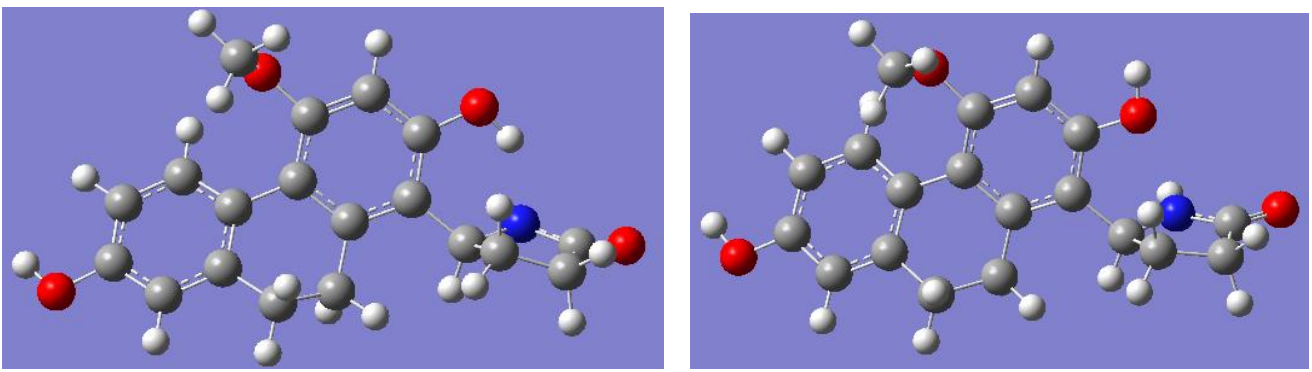

A: $80.93 \%$

B: $3.18 \%$
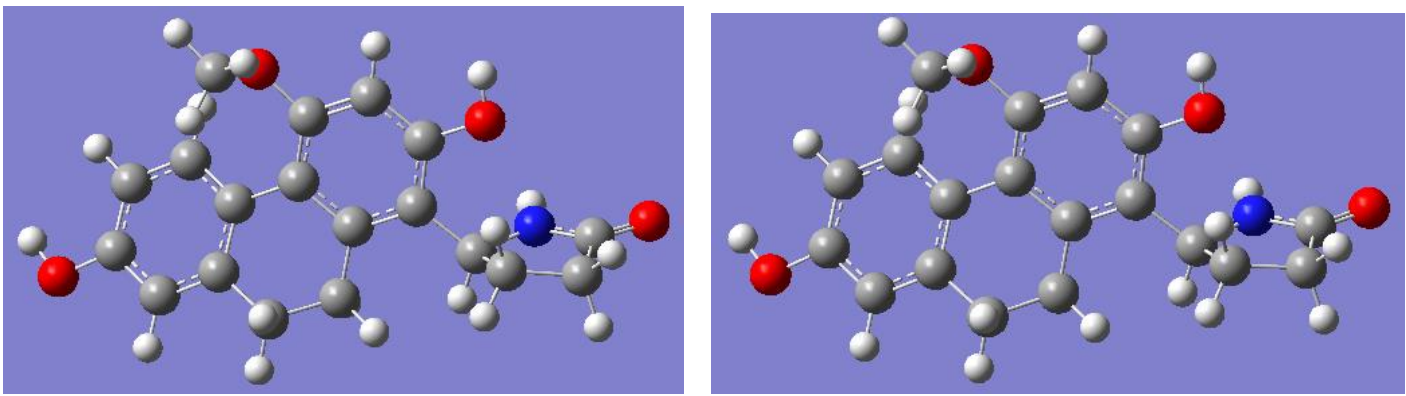

C: $3.18 \%$

D: $3.18 \%$ 
Selected structures and population of the low-energy B3LYP/6-31G (d) in vacuo conformers of $\left(\mathrm{a} R, \mathrm{a}^{\prime} R\right)-\mathbf{2 2}$ based on experimental NOE correlations.
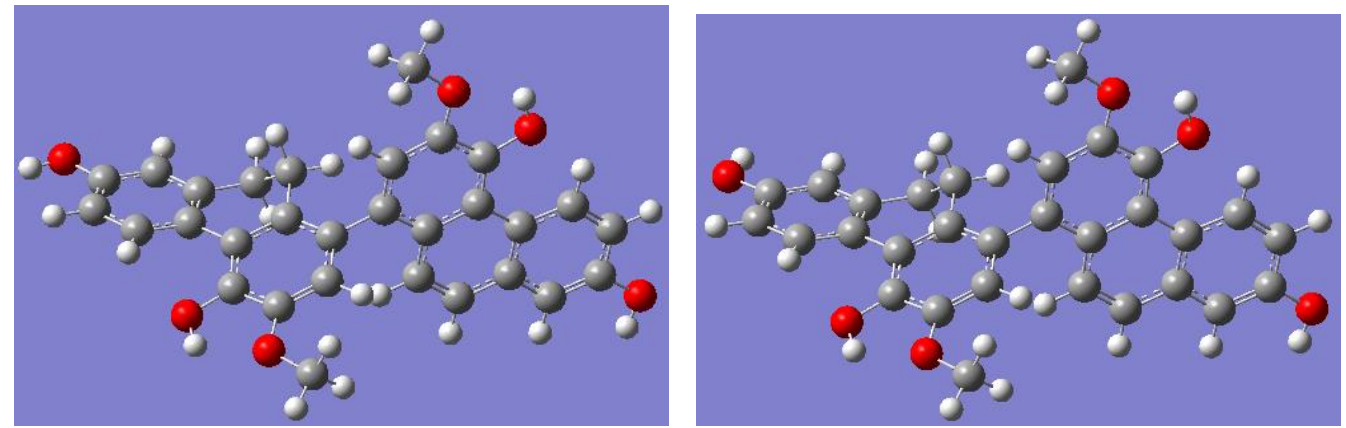

A: $28.64 \%$

B: $27.68 \%$
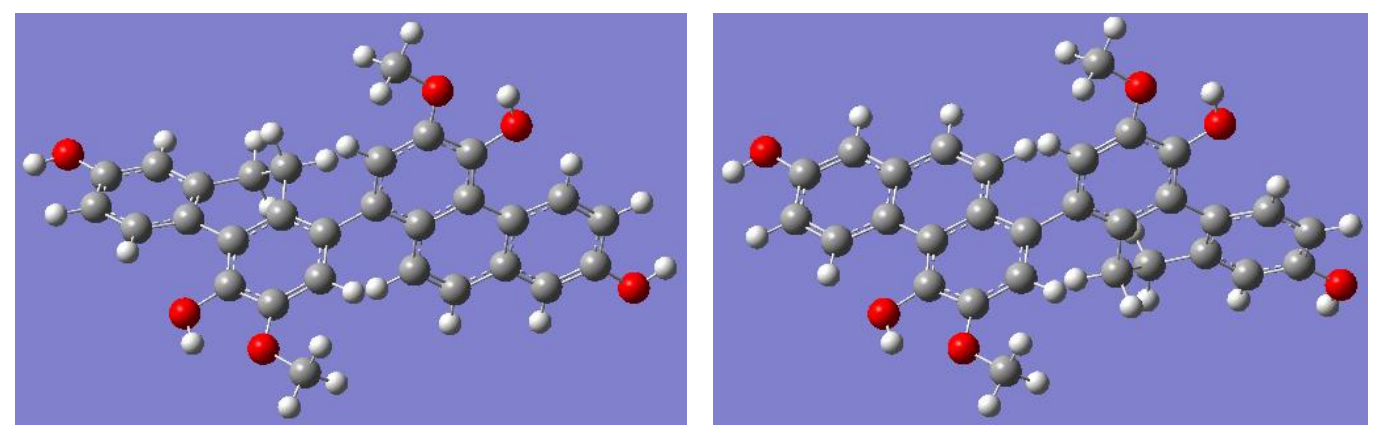

C: $22.15 \%$

D: $21.52 \%$

Selected structures and population of the low-energy B3LYP/6-31G (d) in vacuo conformers of (aS,a'S)-22 based on experimental NOE correlations.
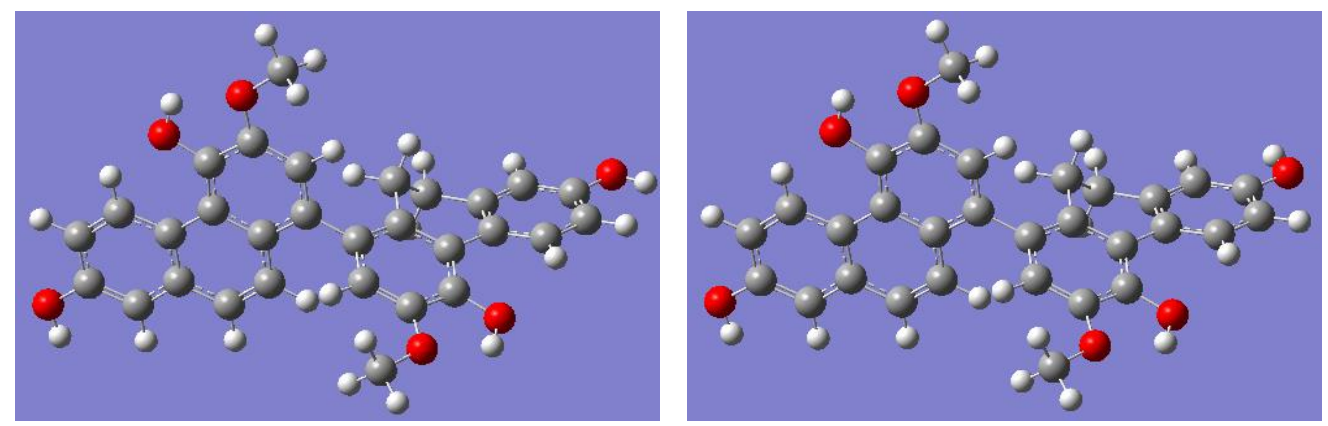

\section{A: $28.64 \%$}

B: $27.68 \%$
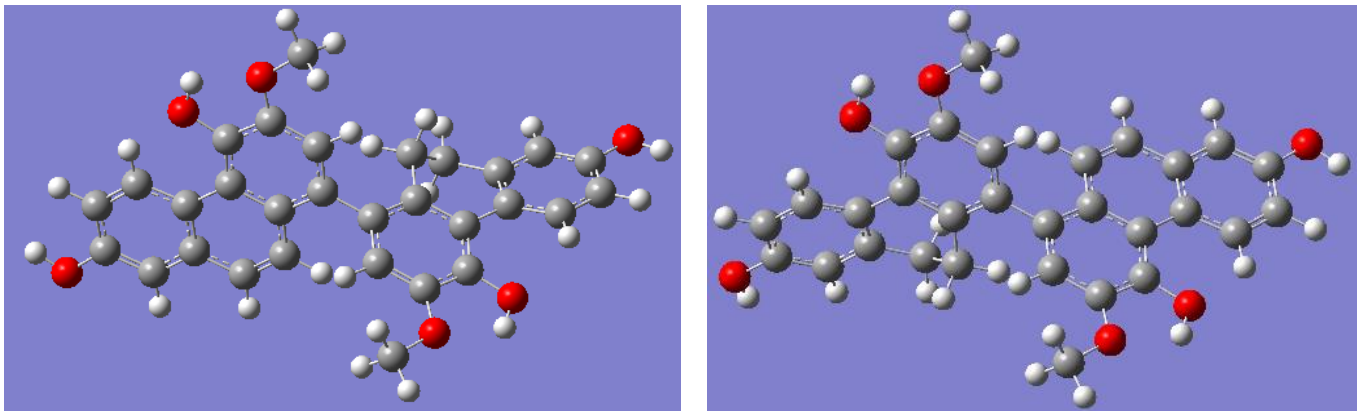

C: $22.15 \%$

D: $21.52 \%$

The distribution of ECD absorbance of compounds $\mathbf{1}$ and $\mathbf{2}$ (Figures R1-R4). 


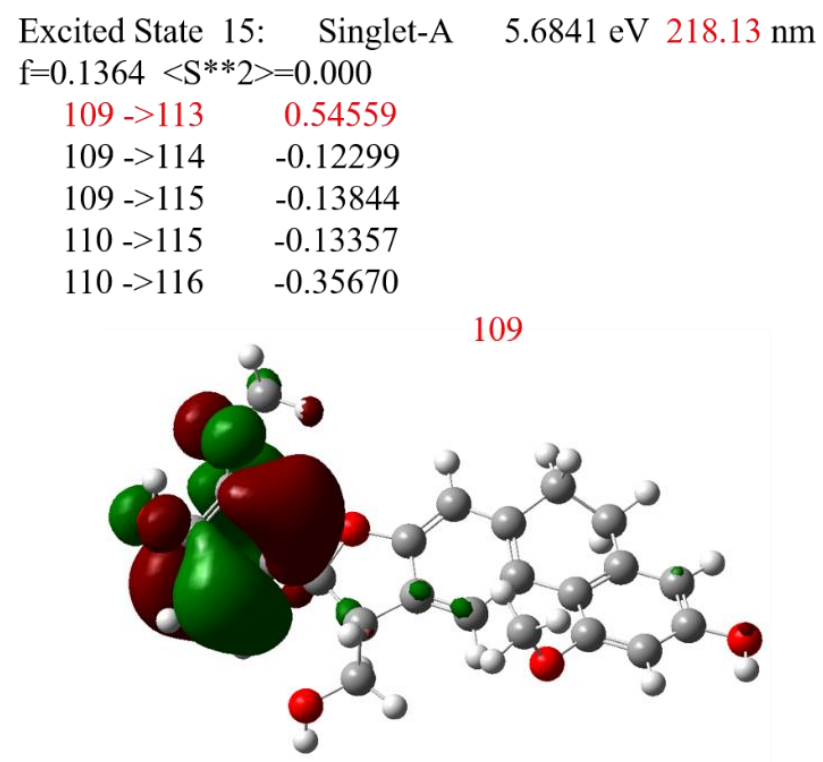

Figure R1
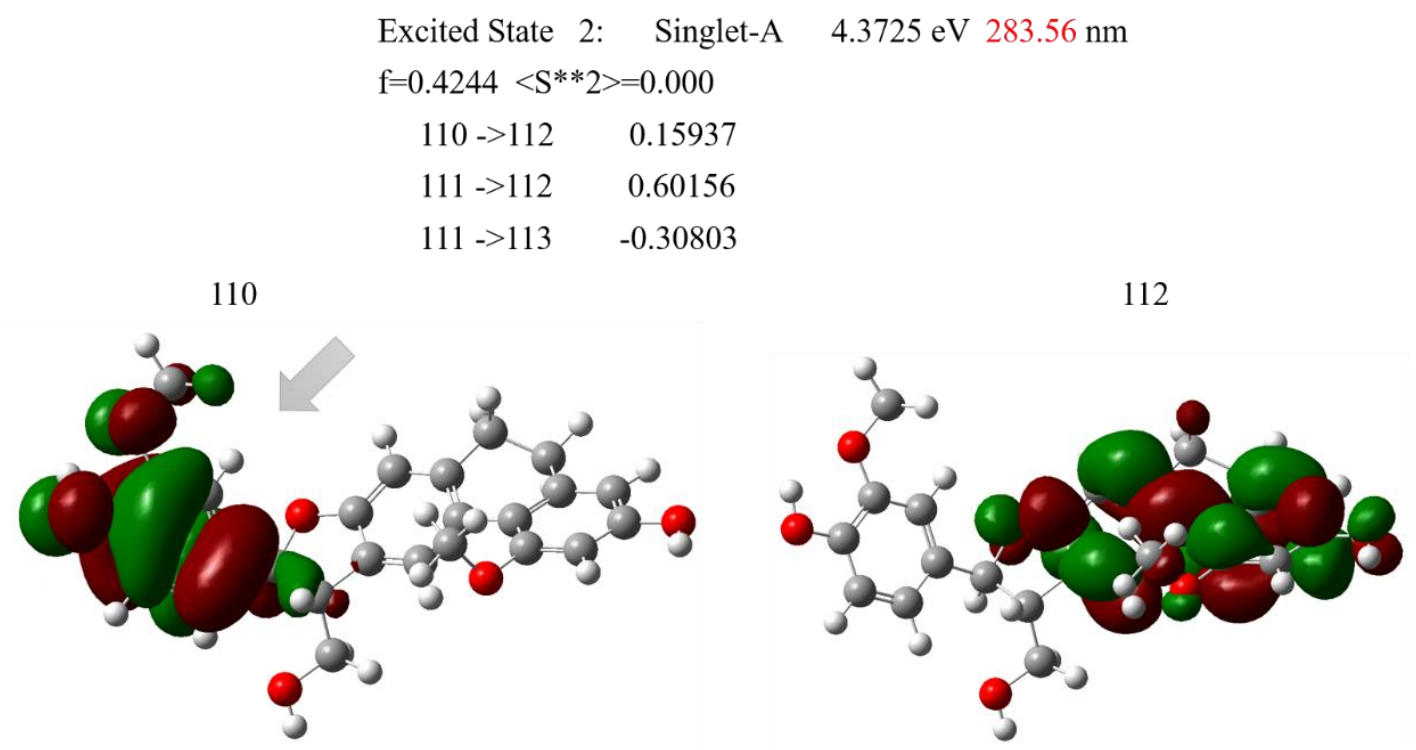

Figure R2 

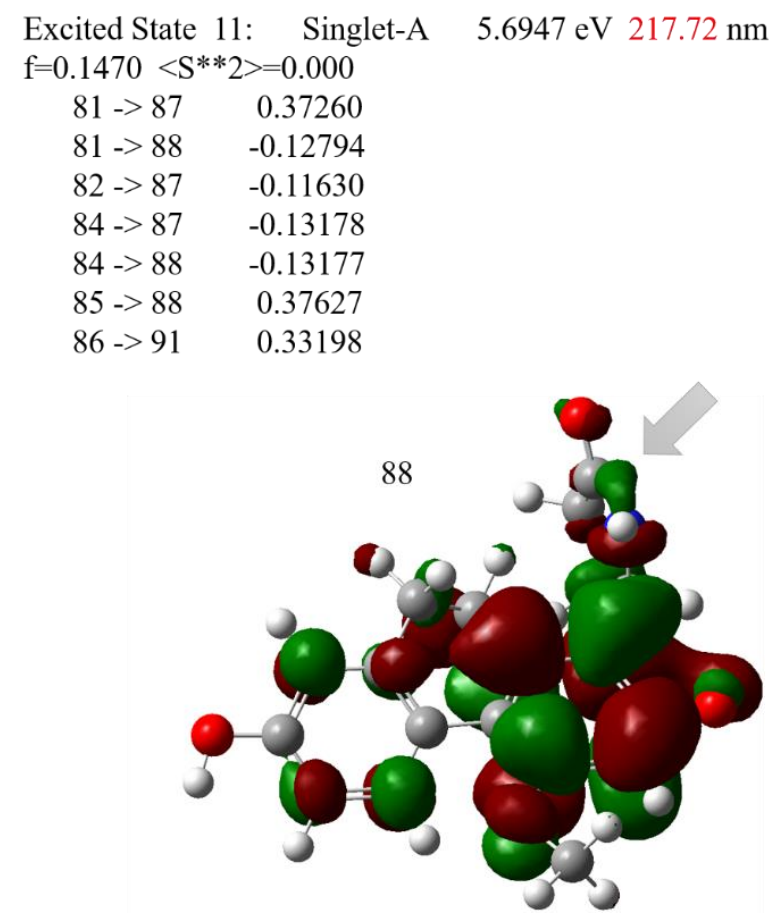

Figure R3
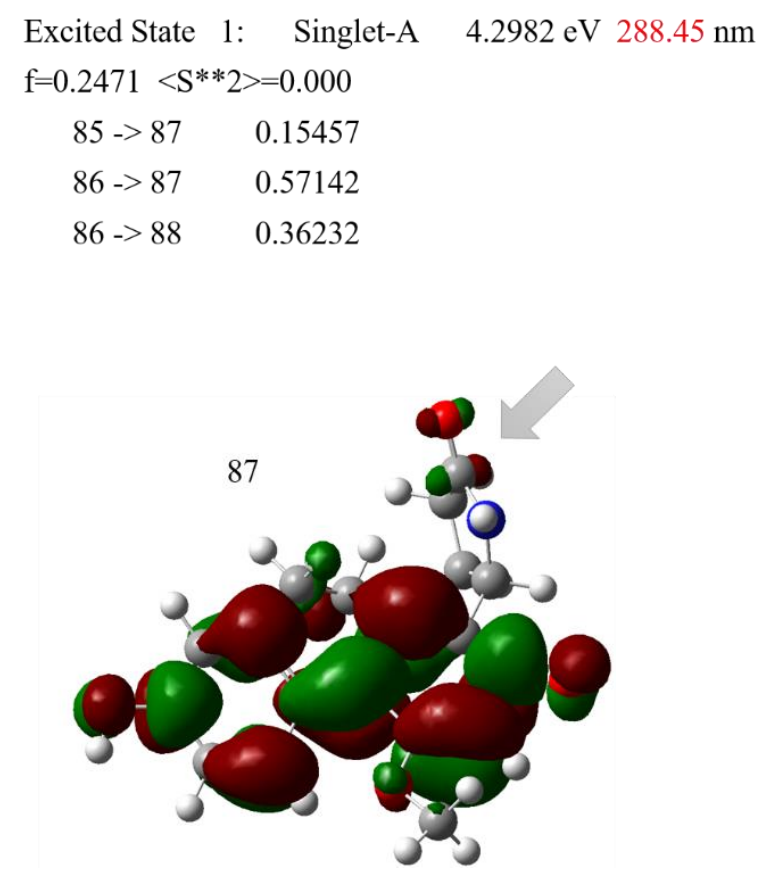

Figure R4

\section{REFERENCES}

(S1) Bruhn,T.; Schaumlöffel, A.; Hemberger, Y.; Pecitelli, G. J. Mol. Med. 2017, 17, 321-329.

(S2) Bruhn, T.; Schaumlöffel, A.; Hemberger, Y.; Bringmann, G. Chirality 2013, 25, 243-249.

(S3) Pescitelli, G.; Bruhn, T. Chirality 2016, 28, 466-47. 
S29. Optical resolution and determination of the absolute configuration of compound $\mathbf{5}$.

Chiral separation of 5 by HPLC with $n$-hexane/EtOH (85/15) afford compounds $\mathbf{5 a}\left(1.5 \mathrm{mg}, \mathrm{t}_{\mathrm{R}}=26\right.$ $\min )$, and $\mathbf{5 b}\left(1.4 \mathrm{mg}, \mathrm{t}_{\mathrm{R}}=29 \mathrm{~min}\right)$. The absolute configurations of $\mathbf{5 a}$ and $\mathbf{5} \mathbf{b}$ were determined by comparison of the cotton effects with those of compound $\mathbf{1}$.

$\left(a S, 7^{\prime} S, 8^{\prime} R\right)$-shanciol $H(5 \boldsymbol{a}):[\alpha]_{\mathrm{D}^{-}}^{20} 20(c 0.1, \mathrm{MeOH}) ; \operatorname{ECD}(\mathrm{MeOH}) \lambda_{\max }(\Delta \varepsilon) 210(-1.37), 280(+5.55) \mathrm{nm}$. $\left(a R, 7^{\prime} R, 8^{\prime} S\right)$-shanciol $H(5 \boldsymbol{b}):[\alpha]_{\mathrm{D}}^{20}+20(c 0.1, \mathrm{MeOH}) ; \mathrm{ECD}(\mathrm{MeOH}) \lambda_{\max }(\Delta \varepsilon) 211(+1.76), 280(+3.11)$ nm.<smiles>COc1cc([C]2Oc3cc4c(cc3[C@@H]2COC2CCCCC2)-c2c(cc(O)cc2OC)CC4)ccc1O</smiles>

$\left(a S, 7^{\prime} S, 8^{\prime} R\right)-5$

$5 a$<smiles>COc1cc([C+]2Oc3cc4c(cc3[C+]2COC(C)=O)-c2c(cc(O)cc2OC)CC4)ccc1O</smiles>

$\left(\mathrm{a} R, 7^{\prime} R, 8^{\prime} S\right)-5$

$\mathbf{5 b}$

Figure S29-A. Chemical structures of $\mathbf{5 a}$ and $\mathbf{5 b}$.

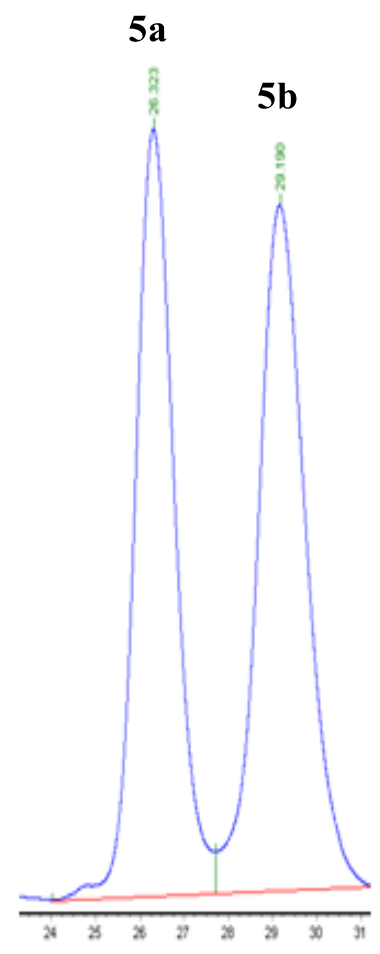

Figure S29-B. Chiral HPLC Chromatograph. 


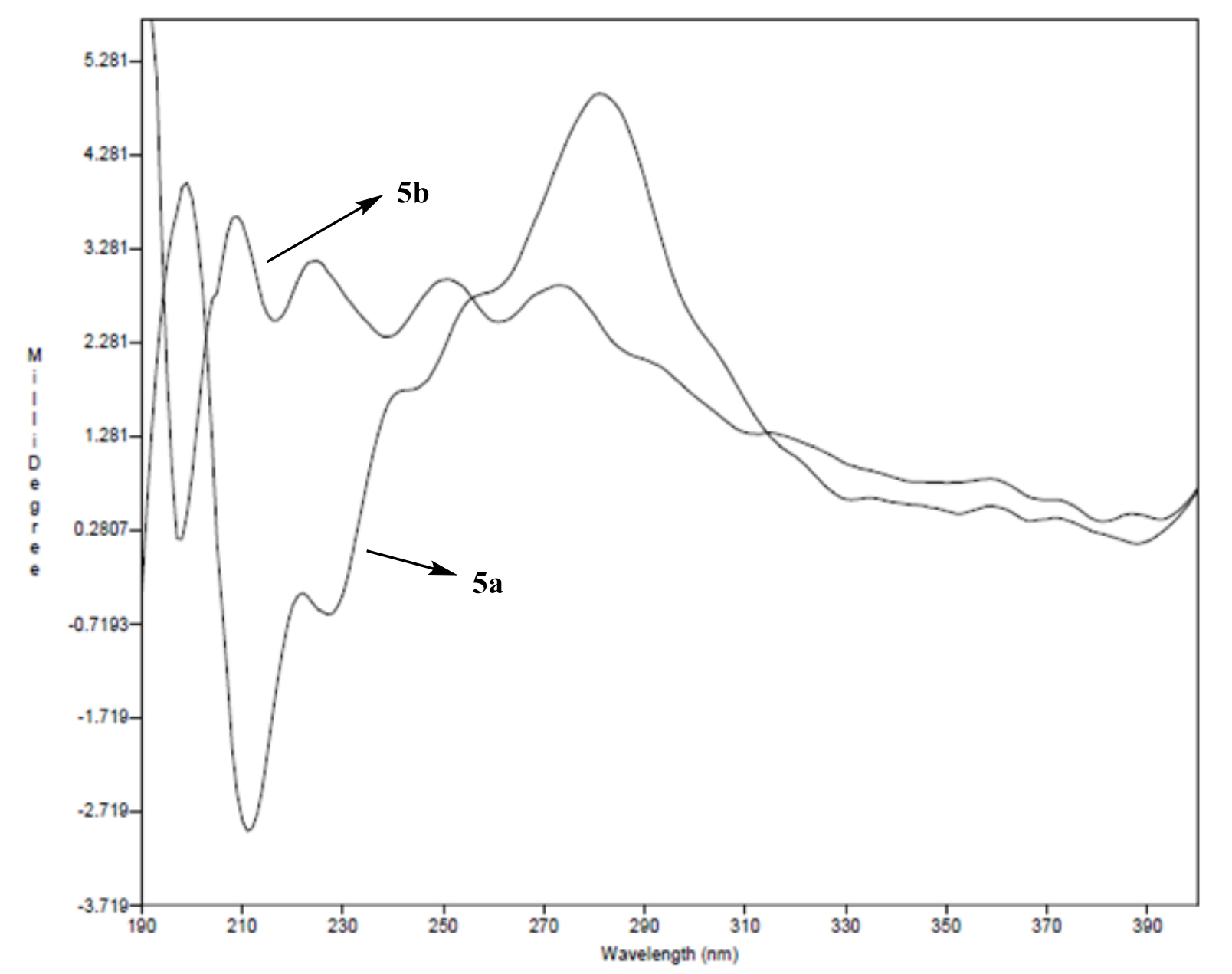

Figure S29-C. ECD spectra of $\mathbf{5 a}$ and $\mathbf{5 b}$. 
S30. Optical resolution and determination of the absolute configuration of compound $\mathbf{8}$.

Chiral separation of 8 by HPLC with $n$-hexane/EtOH (87/13) afford compounds $8 \mathbf{a}\left(1.0 \mathrm{mg}, \mathrm{t}_{\mathrm{R}}=27\right.$ $\min )$, and $\mathbf{8 b}\left(1.0 \mathrm{mg}, \mathrm{t}_{\mathrm{R}}=30 \mathrm{~min}\right)$. The absolute configurations of $\mathbf{8 a}$ and $\mathbf{8 b}$ were determined by comparison of the cotton effects with those of compound $\mathbf{1}$.

$\left(a S, 7^{\prime} S, 8^{\prime} R\right)$-bletilol $C(8 a):[\alpha]_{\mathrm{D}}^{20}-12($ c $0.1, \mathrm{MeOH}) ; \mathrm{ECD}(\mathrm{MeOH}) \lambda_{\max }(\Delta \varepsilon) 212(-2.92), 283(+3.76)$ nm.

$\left(a R, 7^{\prime} R, 8^{\prime} S\right)$-bletilol $C(8 \boldsymbol{b}):[\alpha]_{\mathrm{D}}^{20}+12(c 0.1, \mathrm{MeOH}) ; \mathrm{ECD}(\mathrm{MeOH}) \lambda_{\max }(\Delta \varepsilon) 210(+2.76), 284(-0.89) \mathrm{nm}$.<smiles>COc1cc([C@@H]2COc3cc4c(cc3[C@@H]2OC(C)(F)F)-c2c(cc(O)cc2OC)CC4)ccc1O</smiles>

$\left(a S, 7^{\prime} S, 8^{\prime} R\right)-8$

$8 \mathrm{a}$<smiles>COc1cc([C@@H]2COc3cc4c(cc3[C@@H]2OC(C)=O)-c2c(cc(O)cc2OC)CC4)ccc1O</smiles>

$\left(a R, 7^{\prime} R, 8^{\prime} S\right)-8$

$8 \mathrm{~b}$

Figure S30-A. Chemical structures of $\mathbf{8 a}$ and $\mathbf{8 b}$.

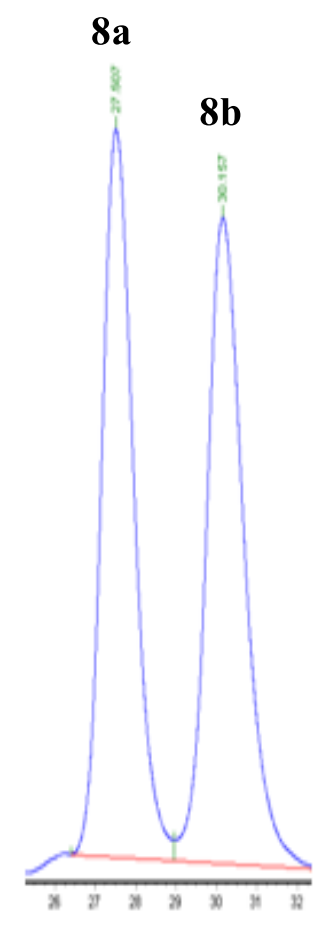

Figure S30-B. Chiral HPLC Chromatograph. 


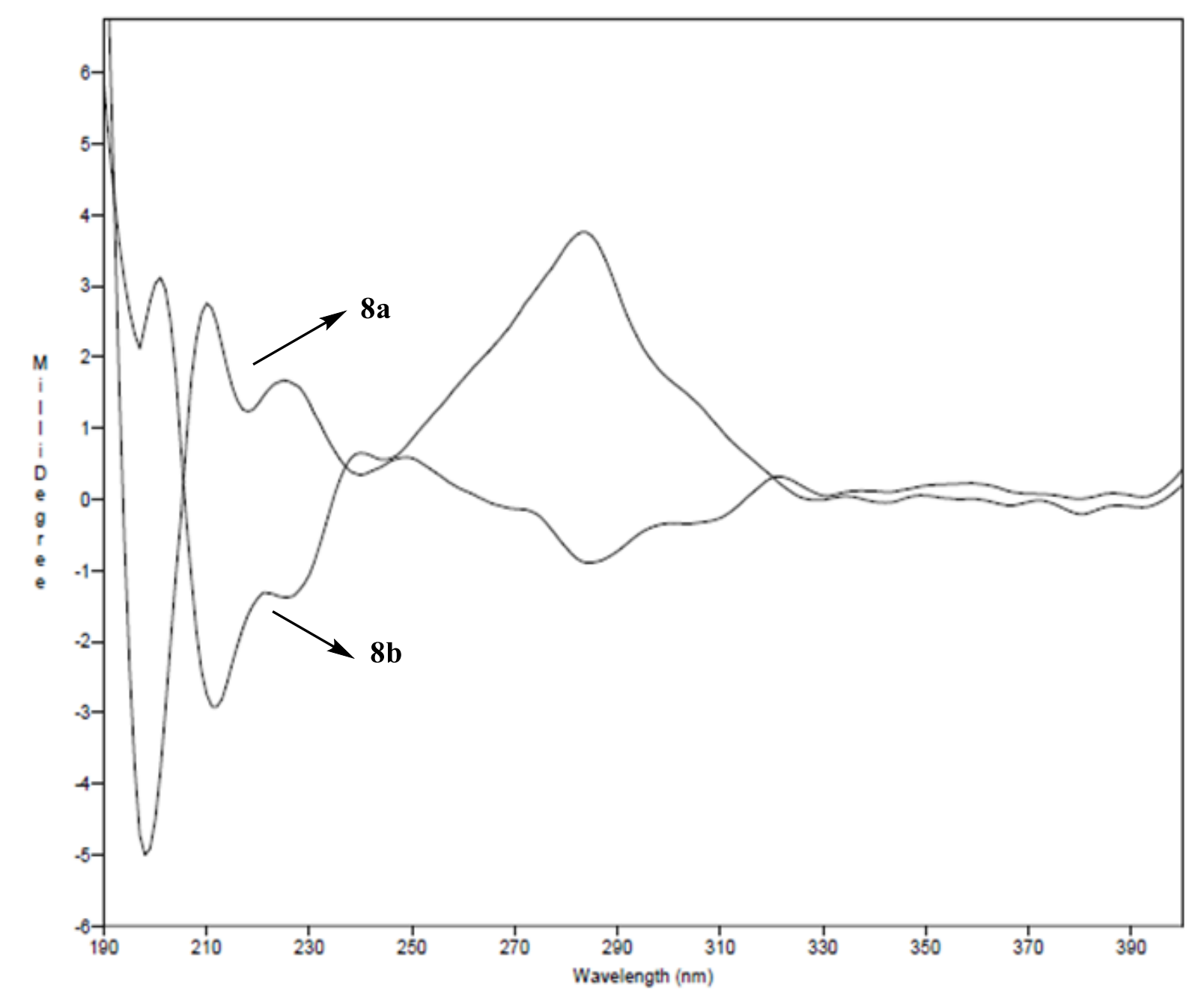

Figure S30-C. ECD spectra of $\mathbf{8 a}$ and $\mathbf{8 b}$. 
S31. Optical resolution and determination of the absolute configuration of compound 9.

Chiral separation of 9 by HPLC with $n$-hexane/EtOH (87/13) afford compounds $9 \mathrm{a}\left(1.3 \mathrm{mg}, \mathrm{t}_{\mathrm{R}}=39\right.$

$\min )$, and $9 \mathbf{b}\left(1.3 \mathrm{mg}, \mathrm{t}_{\mathrm{R}}=42 \mathrm{~min}\right)$. The absolute configurations of $9 \mathbf{a}$ and $9 \mathbf{b}$ were determined by comparison of the cotton effects with those of compound $\mathbf{1}$.

$\left(a S, 7^{\prime} S, 8^{\prime} R\right)$-bletilol B $(\mathbf{9 a}):[\alpha]_{\mathrm{D}}^{20}+22(c 0.1, \mathrm{MeOH}) ; \mathrm{ECD}(\mathrm{MeOH}) \lambda_{\max }(\Delta \varepsilon) 233(-12.23), 282(+8.14) \mathrm{nm}$.

$\left(a R, 7^{\prime} R, 8^{\prime} S\right)$-bletilol B $(\mathbf{9 b}):[\alpha]_{\mathrm{D}}^{20}-22(c 0.1, \mathrm{MeOH}) ; \mathrm{ECD}(\mathrm{MeOH}) \lambda_{\max }(\Delta \varepsilon) 234(+14.05), 282(-10.17)$ $\mathrm{nm}$.<smiles>COc1cc([C@@H]2COc3cc(OC)c4c(c3[C@@H]2OC(C)=O)CCc2cc(O)ccc2-4)ccc1O</smiles>

$\left(\mathrm{aS}, 7^{\prime} S, 8^{\prime} R\right)-9$

9a<smiles>COc1cc([C@@H]2COc3cc(OC)c4c(c3[C+][C@@H]2OC(C)C)CCc2cc(O)ccc2-4)ccc1O</smiles>

$\left(\mathrm{a} R, 7^{\prime} R, 8^{\prime} S\right)-9$

$9 \mathrm{~b}$

Figure S31-A. Chemical structures of $9 \mathbf{a}$ and $9 \mathbf{b}$.

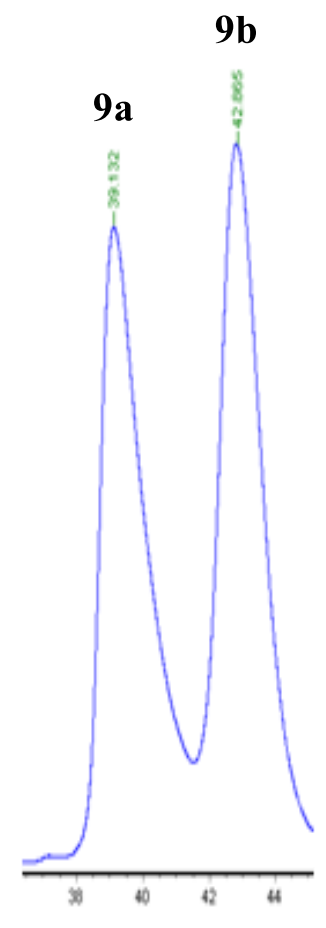

Figure S31-B. Chiral HPLC Chromatograph. 


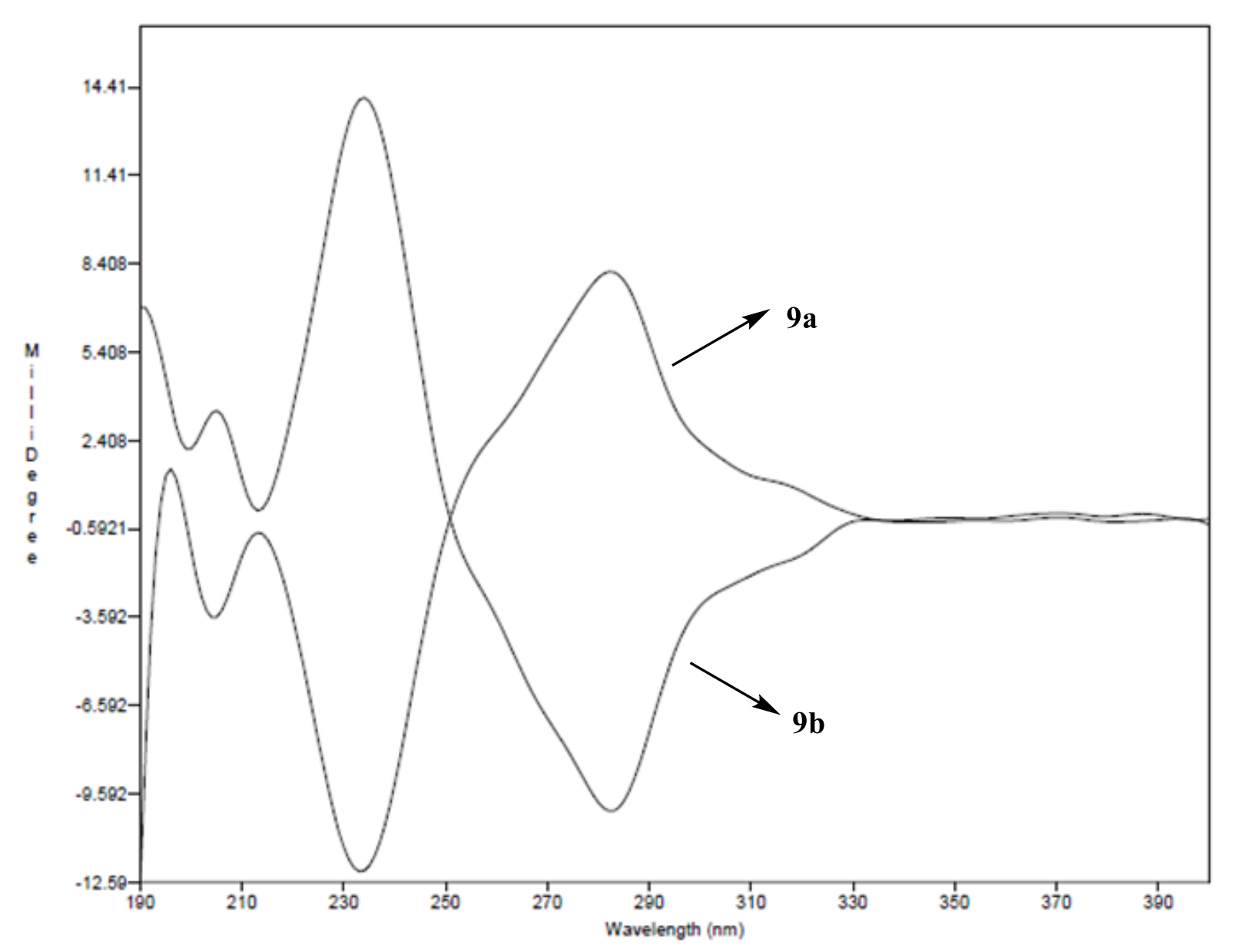

Figure S31-C. ECD spectra of 9a and 9b. 
S32. Optical resolution and determination of the absolute configuration of compound $\mathbf{1 0 .}$

Chiral separation of $\mathbf{1 0}$ by HPLC with $n$-hexane/EtOH (87/13) afford compounds 10a $\left(1.5 \mathrm{mg}, \mathrm{t}_{\mathrm{R}}=43\right.$ $\mathrm{min})$, and $10 \mathrm{~b}\left(1.5 \mathrm{mg}, \mathrm{t}_{\mathrm{R}}=45 \mathrm{~min}\right)$. The absolute configurations of $10 \mathrm{a}$ and $10 \mathrm{~b}$ were determined by comparison of the cotton effects with those of compound $\mathbf{1}$.

$\left(a S, 7^{\prime} S, 8^{\prime} R\right)$-pleionesin $C(\mathbf{1 0 a}):[\alpha]_{\mathrm{D}}^{20}+18(c 0.1, \mathrm{MeOH}) ; \mathrm{ECD}(\mathrm{MeOH}) \lambda_{\max }(\Delta \varepsilon) 236(+0.69), 280(+$ 7.09) $\mathrm{nm}$.

$\left(a R, 7^{\prime} R, 8^{\prime} S\right)$-pleionesin $C(\mathbf{1 0 b}):[\alpha]_{\mathrm{D}}^{20}-18(c 0.1, \mathrm{MeOH}) ; \mathrm{ECD}(\mathrm{MeOH}) \lambda_{\max }(\Delta \varepsilon) 235(+5.53), 281(+0.52)$ nm.

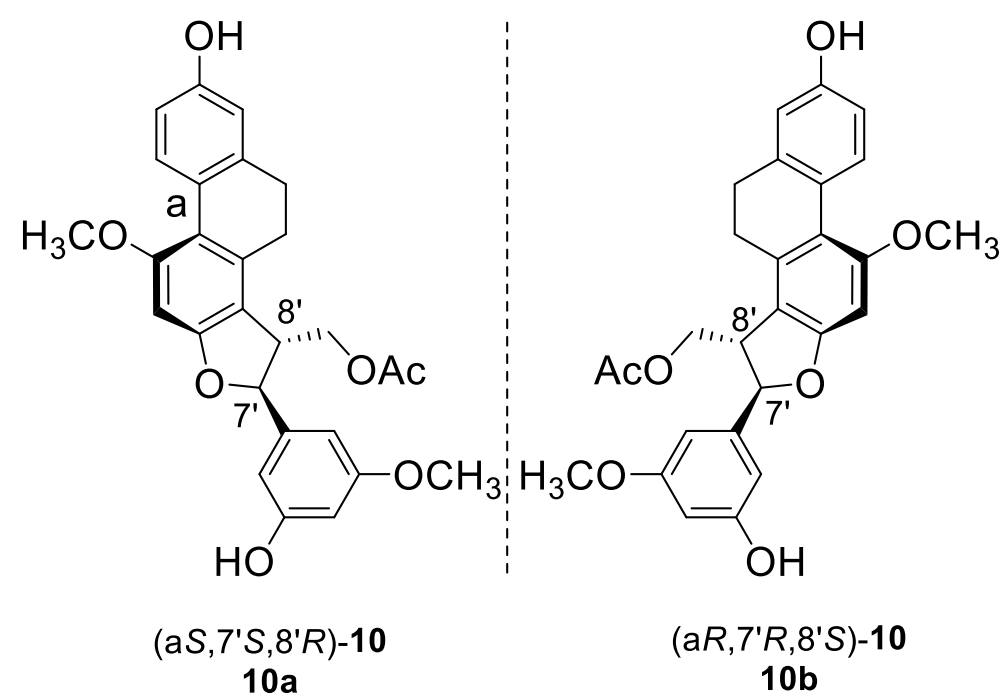

Figure S32-A. Chemical structures of $\mathbf{1 0 a}$ and $\mathbf{1 0 b}$.

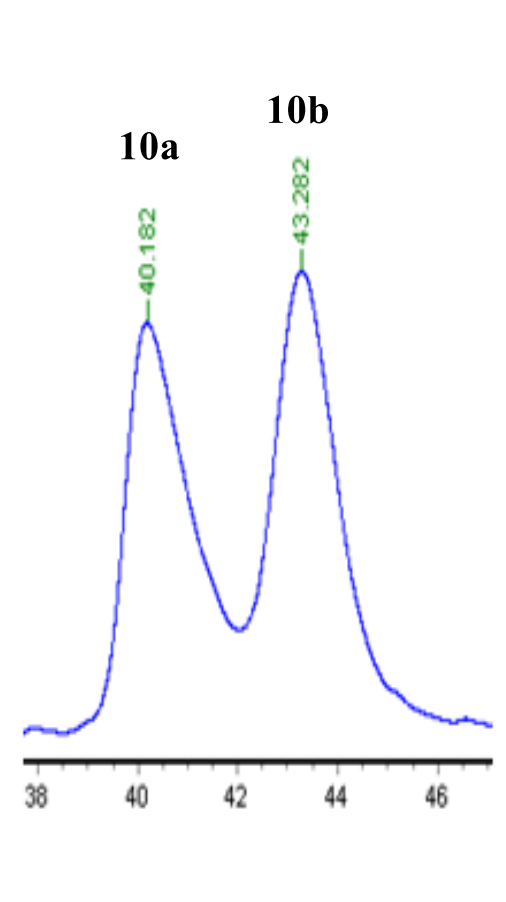

Figure S32-B. Chiral HPLC Chromatograph. 


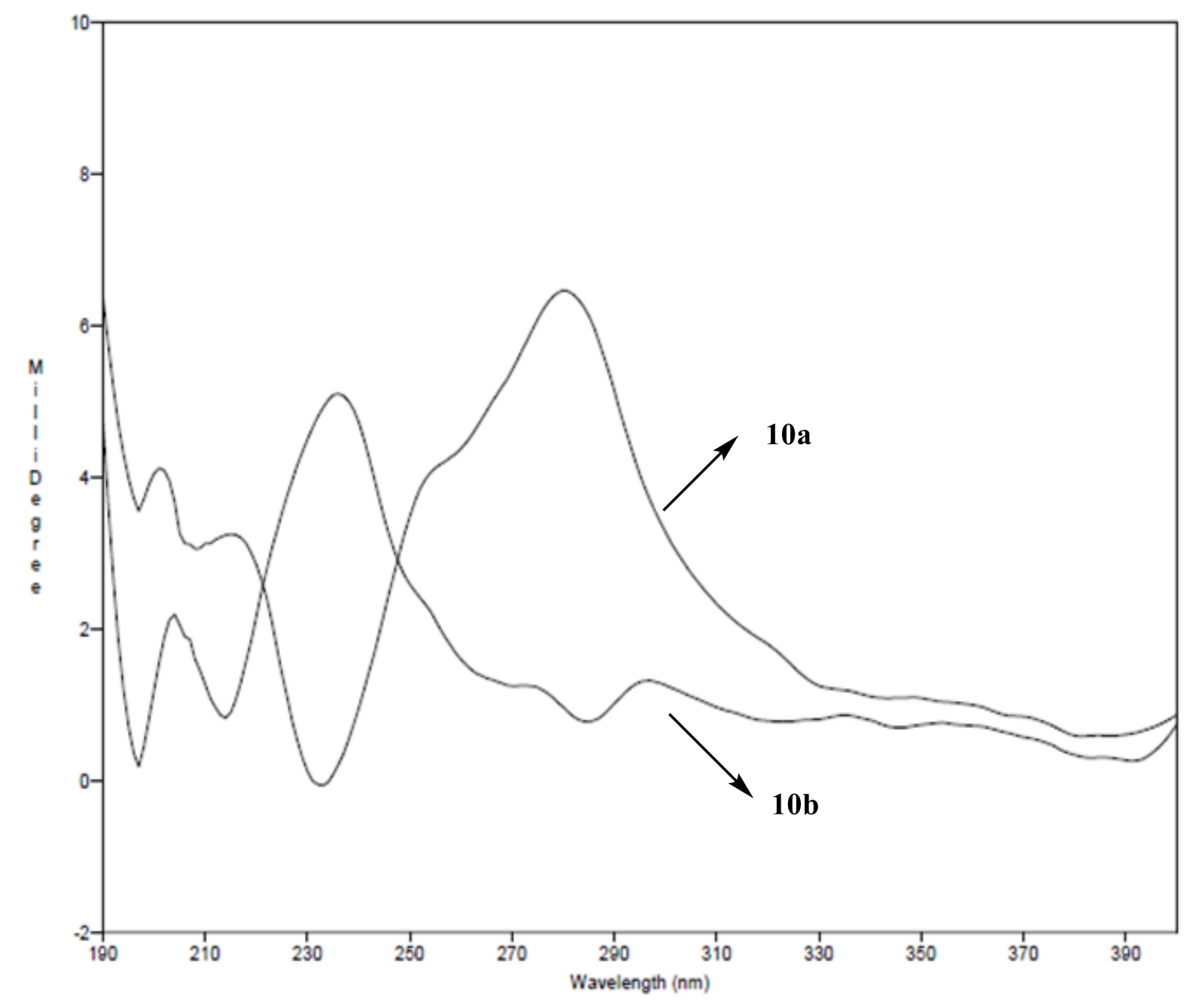

Figure S32-C. ECD spectra of 10a and 10b. 
S33. Optical resolution and determination of the absolute configuration of compound $\mathbf{1 1 .}$

Chiral separation of $\mathbf{1 1}$ by HPLC with $n$-hexane/EtOH (87/13) afford compounds 11a $\left(1.2 \mathrm{mg}, \mathrm{t}_{\mathrm{R}}=24\right.$ $\min )$, and $11 \mathbf{b}\left(1.1 \mathrm{mg}, t_{R}=27 \mathrm{~min}\right)$. The absolute configurations of $11 \mathbf{a}$ and $\mathbf{1 1} \mathbf{b}$ were determined by comparison of the cotton effects with those of compound $\mathbf{1}$.

(aS,7'S, 8'R)-(2,3-trans)-2-(4-hydroxy-3-methoxyphenyl)-3-hydroxymethyl-10-methoxy-2,3,4,5-

tetrahydrophenanthro [2,1-b]furan-7-ol (11a): $[\alpha]_{\mathrm{D}}^{20}+15(c 0.1, \mathrm{MeOH}) ; \mathrm{ECD}(\mathrm{MeOH}) \lambda_{\max }(\Delta \varepsilon) 232(-33.21)$, $284(+25.38) \mathrm{nm}$.

$\left(a R, 7^{\prime} R, 8^{\prime} S\right)-(2,3-t r a n s)-2-(4-h y d r o x y-3-m e t h o x y p h e n y l)-3-h y d r o x y m e t h y l-10-m e t h o x y-2,3,4,5-\quad$ tetrahydrophenanthro [2,1-b]furan-7-ol (11b): $[\alpha]_{\mathrm{D}}^{20}-15(c 0.1, \mathrm{MeOH})$; ECD $(\mathrm{MeOH}) \lambda_{\max }(\Delta \varepsilon) 232(+21.71), 271(-$ $5.01) \mathrm{nm}$.

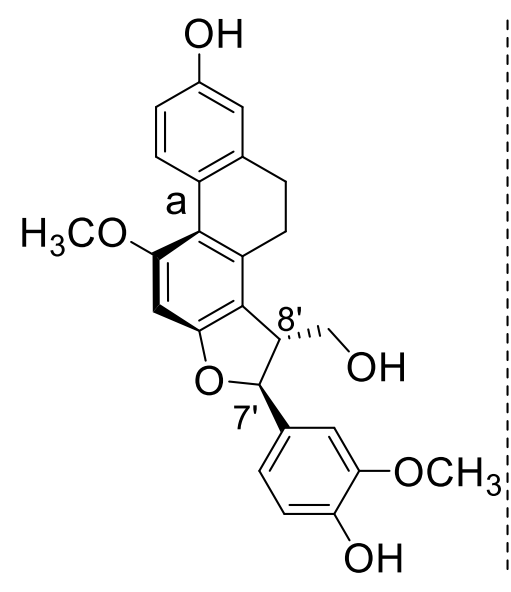

$\left(\mathrm{a} S, 7^{\prime} S, 8^{\prime} R\right)-11$

$11 \mathrm{a}$<smiles>COc1cc([C@]2(C)Oc3cc(OC)c4c(c32)CCc2cc(O)ccc2-4)ccc1O</smiles>

$\left(\mathrm{a} R, 7^{\prime} R, 8^{\prime} S\right)-11$

$11 \mathrm{~b}$

Figure S33-A. Chemical structures of 11a and $\mathbf{1 1 b .}$

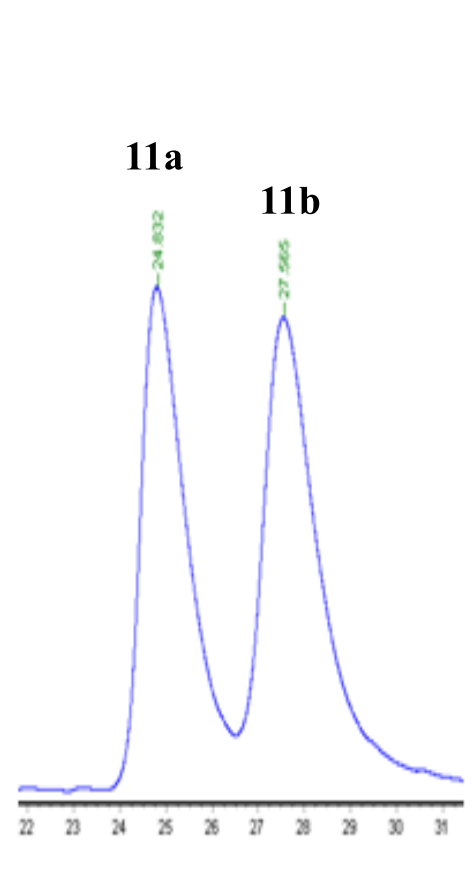

Figure S33-B. Chiral HPLC Chromatograph. 


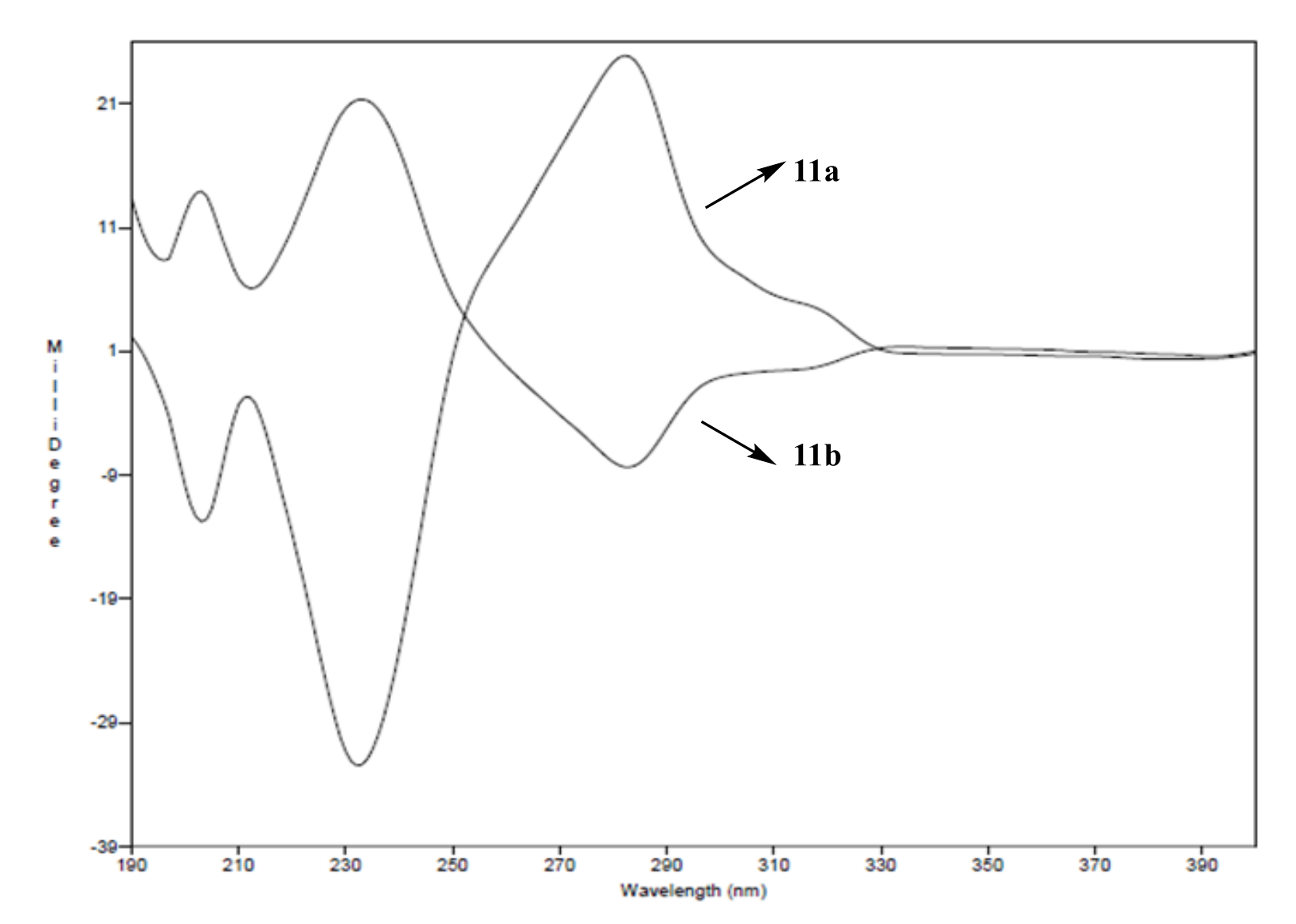

Figure S33-C. ECD spectra of 11a and 11b. 
S34. Optical resolution and determination of the absolute configuration of compound $\mathbf{1 3 .}$

Chiral separation of $\mathbf{1 3}$ by HPLC with $n$-hexane/EtOH (85/15) afford compounds 13a $\left(1.1 \mathrm{mg}, \mathrm{t}_{\mathrm{R}}=6\right.$ $\min )$, and $13 \mathbf{b}\left(1.1 \mathrm{mg}, \mathrm{t}_{\mathrm{R}}=10 \mathrm{~min}\right)$. The absolute configurations of 13a and 13b were determined by comparison of the cotton effects with those of compound 2.

(aS)-1,4,7-trihydroxy-2- methoxy-9,10-dihydrophenanthrene $(13 a):[\alpha]_{\mathrm{D}}^{20}+35(c$ 0.1, $\mathrm{MeOH}) ; \mathrm{ECD}(\mathrm{MeOH})$ $\lambda_{\max }(\Delta \varepsilon) 206(+0.70), 237(+0.95), 279(+2.12), 315(+0.42) \mathrm{nm}$.

(aR)-1, 4,7-trihydroxy-2-methoxy-9,10-dihydrophenanthrene $(\mathbf{1 3 b}):[\alpha]_{\mathrm{D}}^{20}-35(c 0.1, \mathrm{MeOH}) ; \mathrm{ECD}(\mathrm{MeOH})$ $\lambda_{\max }(\Delta \varepsilon) 206(+6.32), 238(-3.17), 277(-5.22), 309(-2.18) \mathrm{nm}$.<smiles>COc1cc(O)c2c(c1O)CCc1cc(O)ccc1-2</smiles>

(aS)-13

$13 a$<smiles>COc1cc(O)c2c(c1O)CCc1cc(O)ccc1-2</smiles>

Figure S34-A. Chemical structures of $13 \mathbf{a}$ and $13 b$.

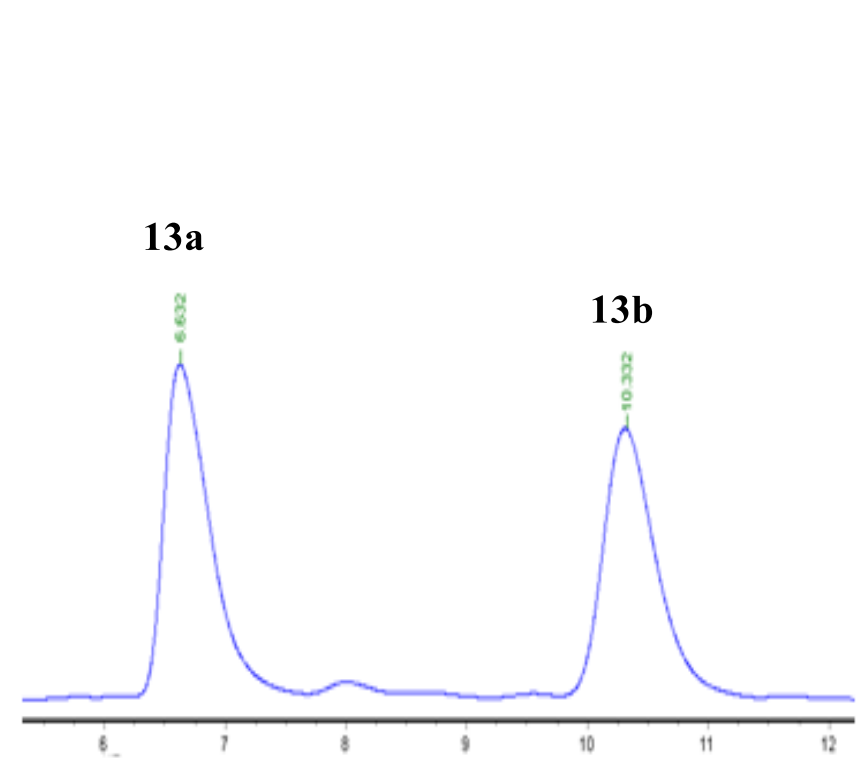

Figure S34-B. Chiral HPLC Chromatograph. 


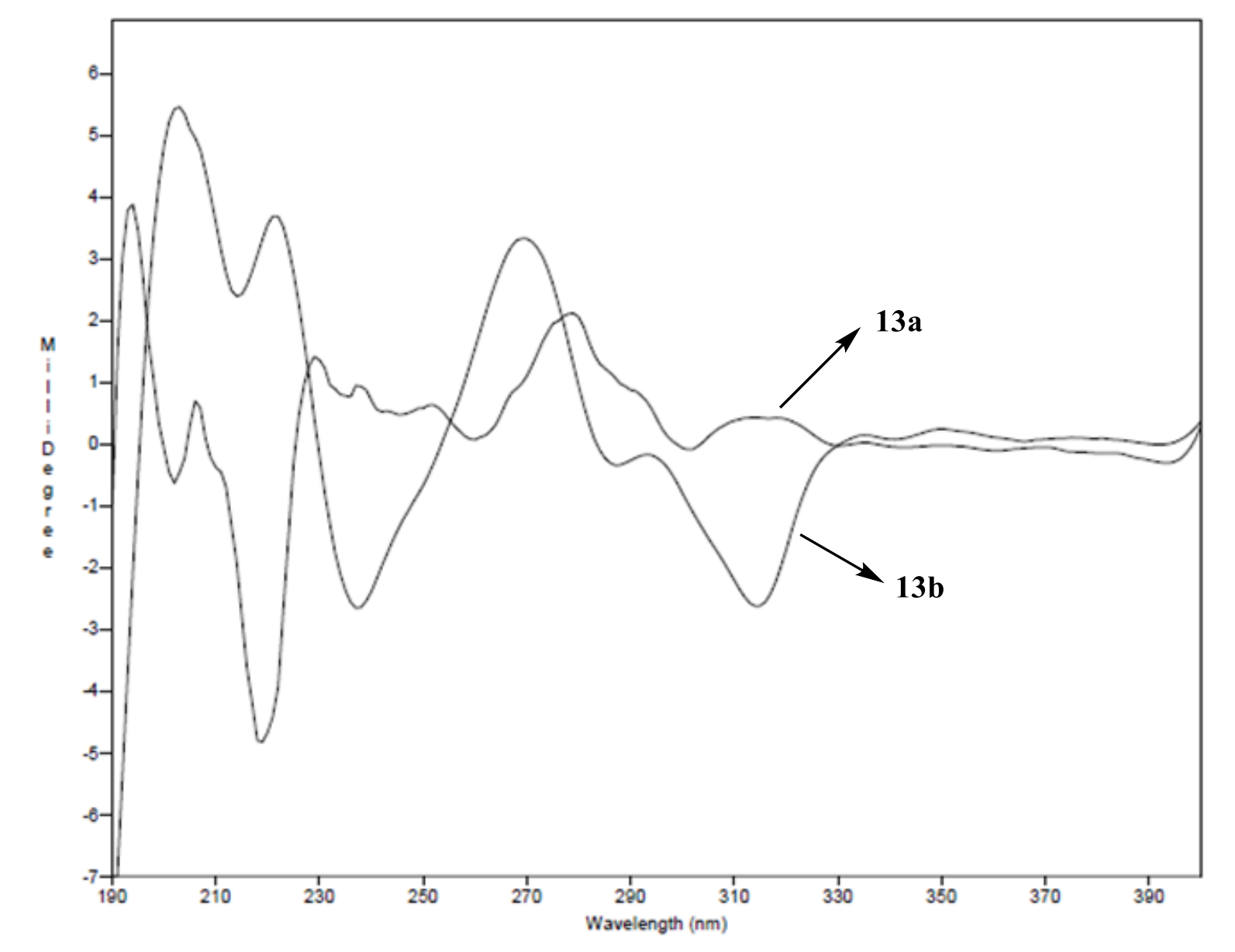

Figure S34-C. ECD spectra of $\mathbf{1 3 a}$ and $\mathbf{1 3 b}$. 
S35. Optical resolution and determination of the absolute configuration of compound 22.

Chiral separation of 22 by HPLC with $n$-hexane/EtOH (85/15) afford compounds 22a $\left(1.9 \mathrm{mg}, \mathrm{t}_{\mathrm{R}}=18\right.$ $\min )$, and $\mathbf{2 2} \mathbf{b}\left(1.8 \mathrm{mg}, \mathrm{t}_{\mathrm{R}}=32 \mathrm{~min}\right)$. The absolute configurations of $\mathbf{2 2 \mathbf { a }}$ and $\mathbf{2 2} \mathbf{b}$ were determined by comparison of the experimental and calculated ECD.

(aR, $\left.a^{\prime} R\right)$-blestriarene $B(\mathbf{2 2 a}):[\alpha]_{\mathrm{D}}^{20}-33(c 0.1, \mathrm{MeOH}) ; \mathrm{ECD}(\mathrm{MeOH}) \lambda_{\max }(\Delta \varepsilon) 205(+26.78), 218(-4.20)$, 233 (+2.29), $247(-1.30), 261(+5.93)$, and $281(-8.59) \mathrm{nm}$.

$\left(a S, a^{\prime} S\right)-$ blestriarene $B(\mathbf{2 2 b}):[\alpha]_{\mathrm{D}}^{20}+33(c 0.1, \mathrm{MeOH})$; $\mathrm{ECD}(\mathrm{MeOH}) \lambda_{\max }(\Delta \varepsilon) 205(-12.81), 218(+4.42)$, $235(+1.05), 245(+2.57), 261(-2.03)$, and $281(+6.51) \mathrm{nm}$.<smiles>COc1cc(O)c(-c2c(O)cc(OC)c3c2ccc2cc(O)ccc23)c2c1[C@H]1C=CC(O)=CC1CC2</smiles>

(aS,a'S)-22

22b<smiles>COc1cc(O)c(-c2c(O)cc(OC)c3c2ccc2cc(O)ccc23)c2c1[Ge]c1ccc(O)cc1CC2</smiles>
$\left(\mathrm{a} R, \mathrm{a}^{\prime} S\right)-22$<smiles>COc1cc(O)c(-c2c(O)cc(OC)c3c2ccc2cc(O)ccc23)c2c1[C@H]1C=CC(O)=CC1CC2</smiles>

$\left(\mathrm{a} R, \mathrm{a}^{\prime} R\right)-22$

$22 \mathrm{a}$

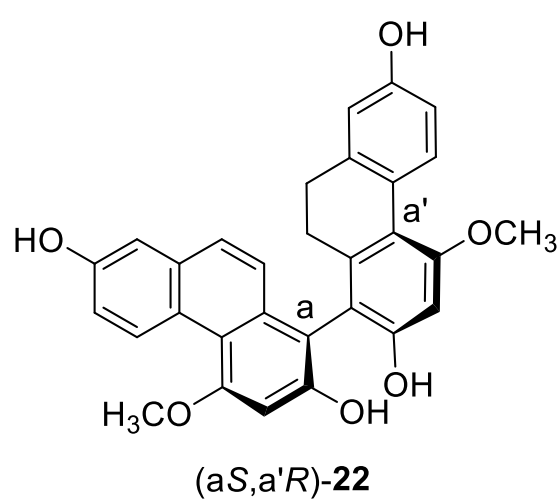

Figure S35-A. Chemical structures of four configurations of 22. 


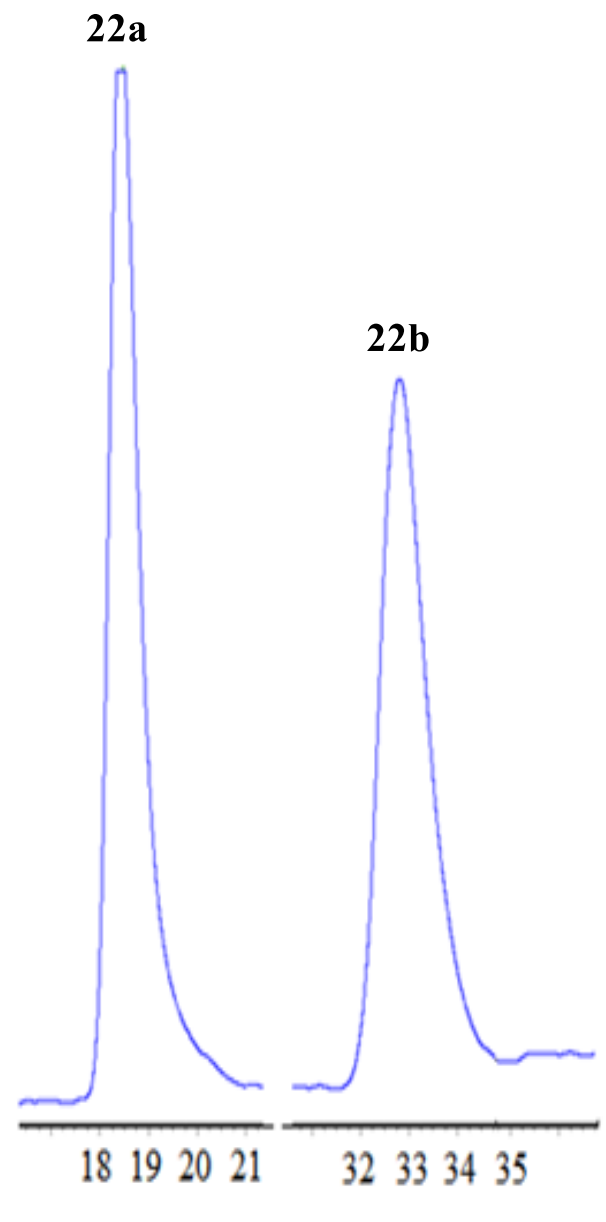

Figure S35-B. Chiral HPLC Chromatograph.

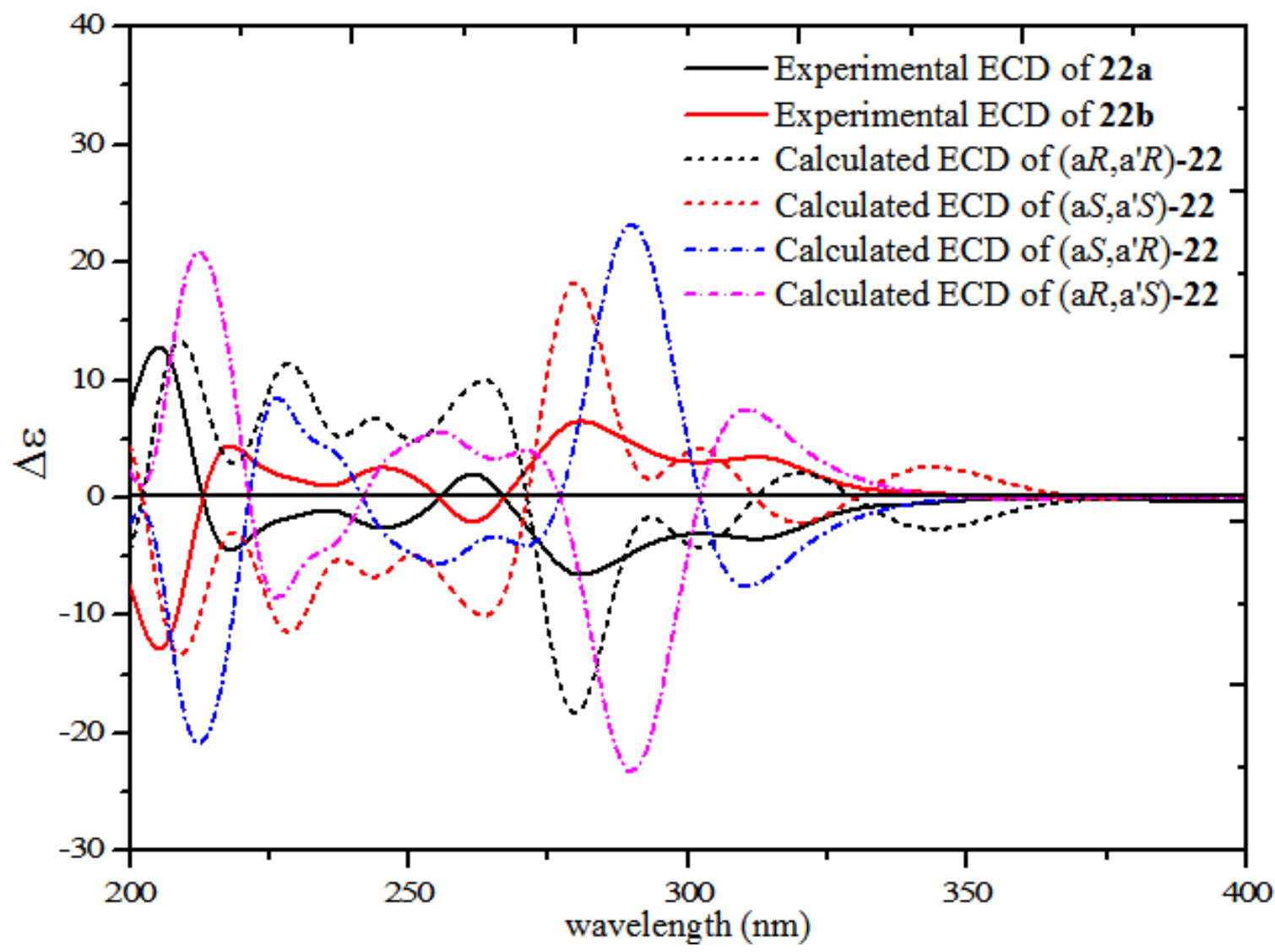

Figure S35-C. Experimental and calculated ECD spectra of 22a and 22b. 
S36. Optical resolution and determination of the absolute configuration of compound 25.

Chiral separation of $\mathbf{2 5}$ by HPLC with $n$-hexane/EtOH (85/15) afford compounds $\mathbf{2 5 a}\left(1.5 \mathrm{mg}, \mathrm{t}_{\mathrm{R}}=15\right.$

$\min )$, and $25 \mathbf{b}\left(1.6 \mathrm{mg}, \mathrm{t}_{\mathrm{R}}=29 \mathrm{~min}\right)$. The absolute configurations of $25 \mathbf{a}$ and $25 \mathbf{b}$ were determined by comparison of the cotton effects with reference compounds. ${ }^{\mathrm{S} 4}$

(aR $\left.a^{\prime} S, a^{\prime \prime} R\right)-$ blestriarene A (25a): $[\alpha]_{\mathrm{D}}^{20}-30(c 0.1, \mathrm{MeOH}) ; \mathrm{ECD}(\mathrm{MeOH}) \lambda_{\max }(\Delta \varepsilon) 219(+9.56), 235(-8.59)$, $268(+7.04), 313(-7.68) \mathrm{nm}$.

$\left(a S, a^{\prime} R, a^{\prime \prime} S\right)$-blestriarene $A(25 b):[\alpha]_{\mathrm{D}}^{20}+30(c 0.1, \mathrm{MeOH}) ; \mathrm{ECD}(\mathrm{MeOH}) \lambda_{\max }(\Delta \varepsilon) 219(-7.47), 234(+8.01)$, $270(-6.44), 314(+7.59) \mathrm{nm}$.
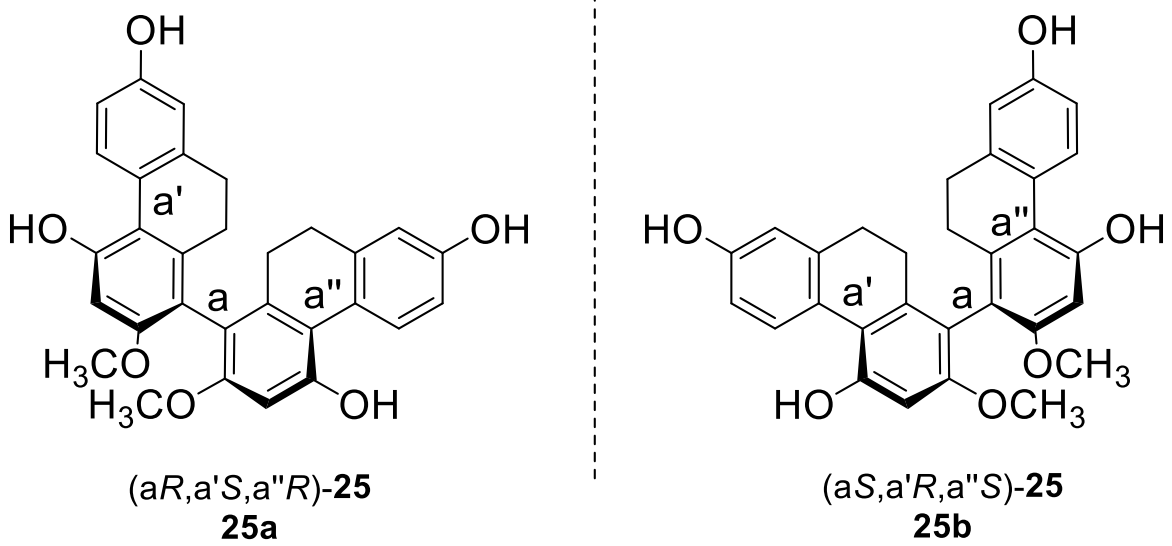

Figure S36-A. Chemical structures of 25a and 25b.

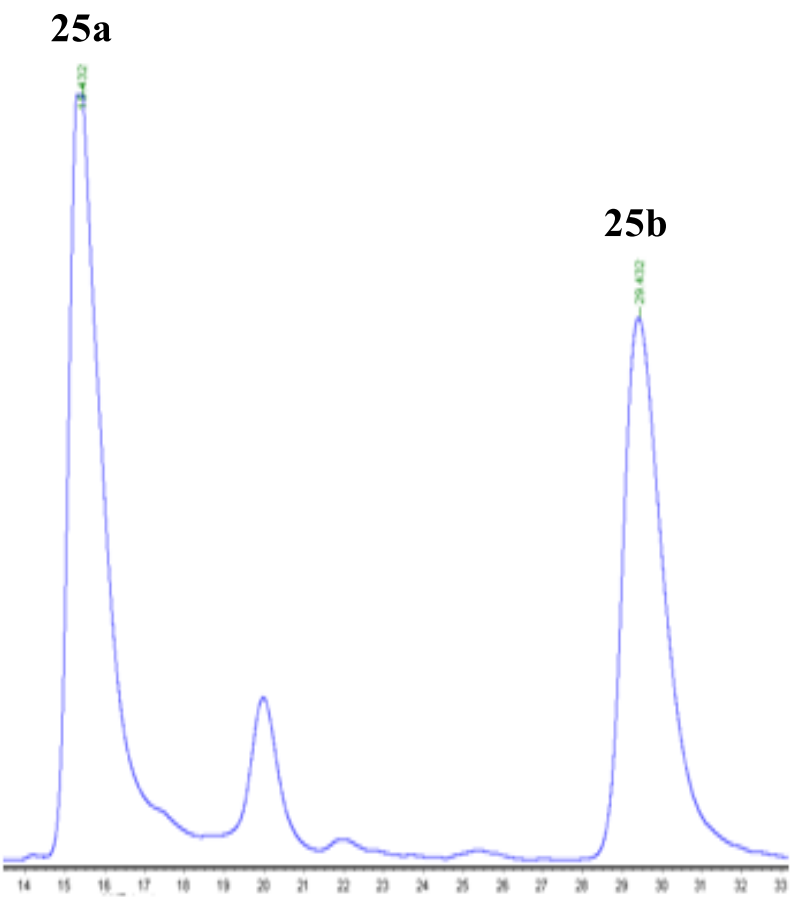

Figure S36-B. Chiral HPLC Chromatograph. 


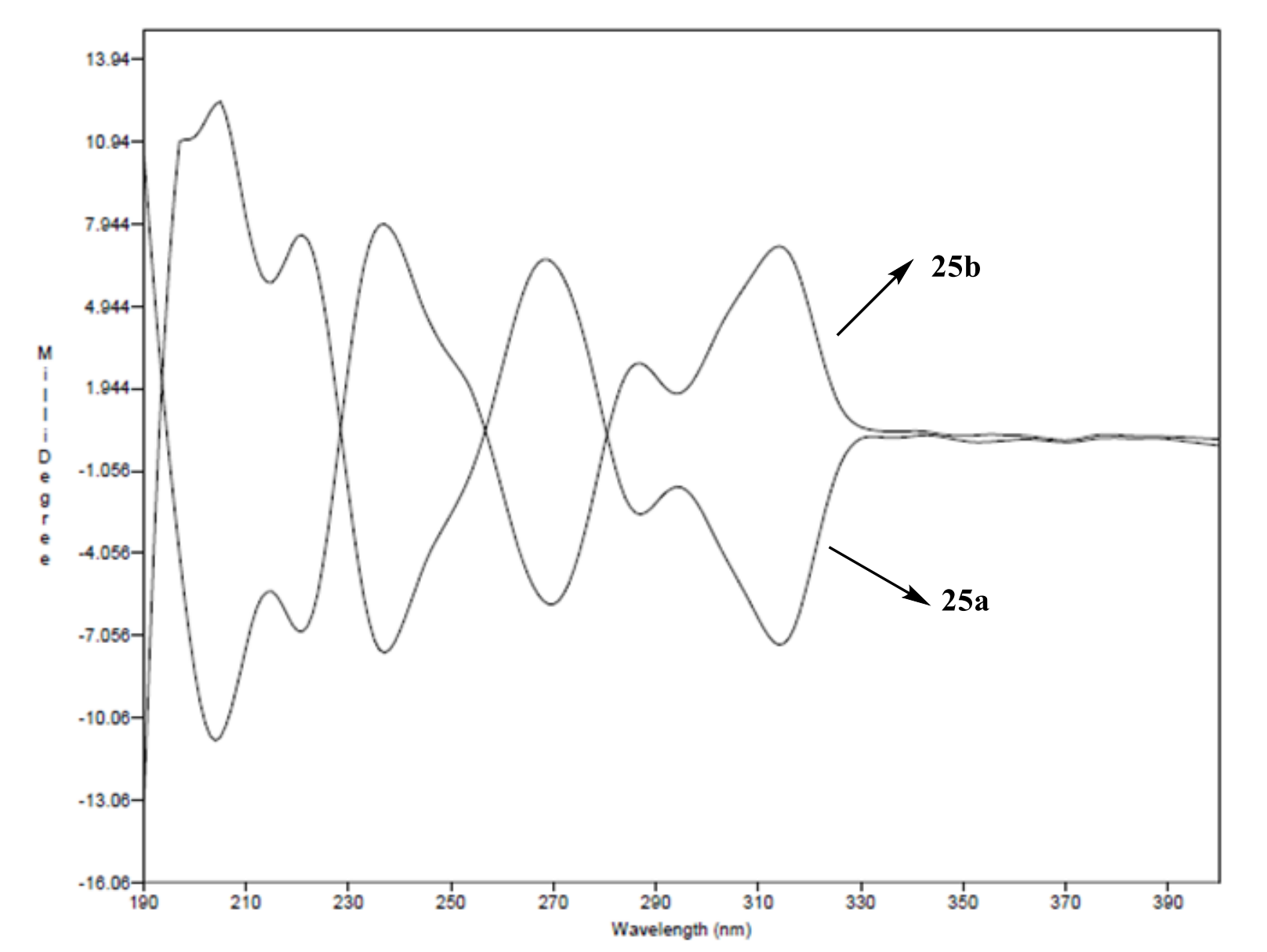

Figure S36-C. ECD spectra of $25 \mathbf{a}$ and $\mathbf{2 5 b}$.

\section{REFERENCES}

(S4) Yao, S.; Tang, C. P.; Ye, Y.; Kurtan, T.; Kiss-Szikszai, A.; Antus, S.; Pescitelli, G.; Salvadori, P.; Krohn, K. Tetrahedron Asymmetry 2008, 19, 2007-2014. 
S37. Optical resolution and determination of the absolute configuration of compound $\mathbf{3 3}$.

Chiral separation of $\mathbf{3 3}$ by HPLC with $n$-hexane/EtOH (85/15) afford compounds 33a $\left(1.4 \mathrm{mg}, \mathrm{t}_{\mathrm{R}}=16\right.$ $\min )$, and $33 \mathbf{b}\left(1.3 \mathrm{mg}, \mathrm{t}_{\mathrm{R}}=29 \mathrm{~min}\right)$. The absolute configurations of 33a and 33b were determined by comparison of the cotton effects with reference compounds. ${ }^{\mathrm{S}}$

(aS)-4,8,4', 8'-tetramethoxy-(1,1'-biphenanthrene)-2,7,2',7'-tetrol (33a): $[\alpha]_{\mathrm{D}}^{20}+45($ c $0.1, \mathrm{MeOH}) ; \mathrm{ECD}$ $(\mathrm{MeOH}) \lambda_{\max }(\Delta \varepsilon) 208(-21.16), 249(+15.28) \mathrm{nm}$.

(aR)-4,8,4', $8^{\prime}$-tetramethoxy-(1,1'-biphenanthrene)-2,7,2',7'-tetrol (33b): $[\alpha]_{\mathrm{D}}^{20}-45(c 0.1, \mathrm{MeOH}) ; \mathrm{ECD}$ $(\mathrm{MeOH}) \lambda_{\max }(\Delta \varepsilon) 208(+31.41), 249(-6.26) \mathrm{nm}$.<smiles>COc1cc(O)c(O)c2ccc(O)c(OC)c12</smiles>

(aS)-33

33a<smiles></smiles>

$(\mathrm{a} R)-33$

33b

Figure S37-A. Chemical structures of $\mathbf{3 3 a}$ and $\mathbf{3 3 b}$.

\section{$33 \mathbf{a}$}

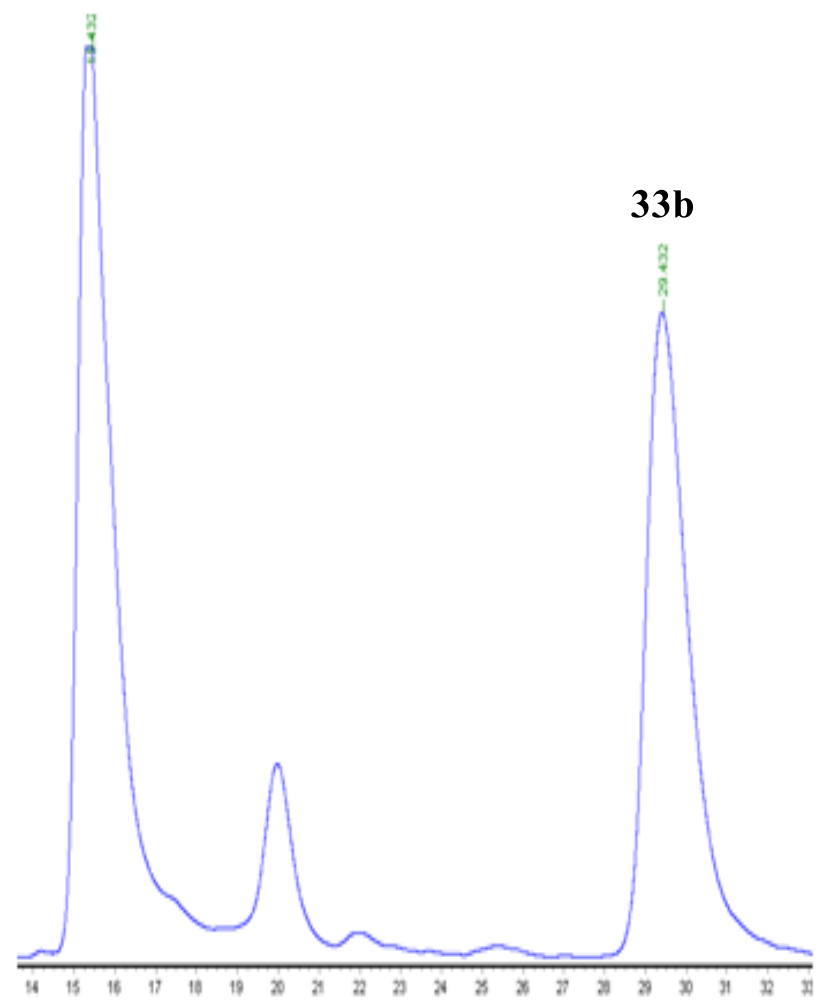

Figure S37-B. Chiral HPLC Chromatograph. 


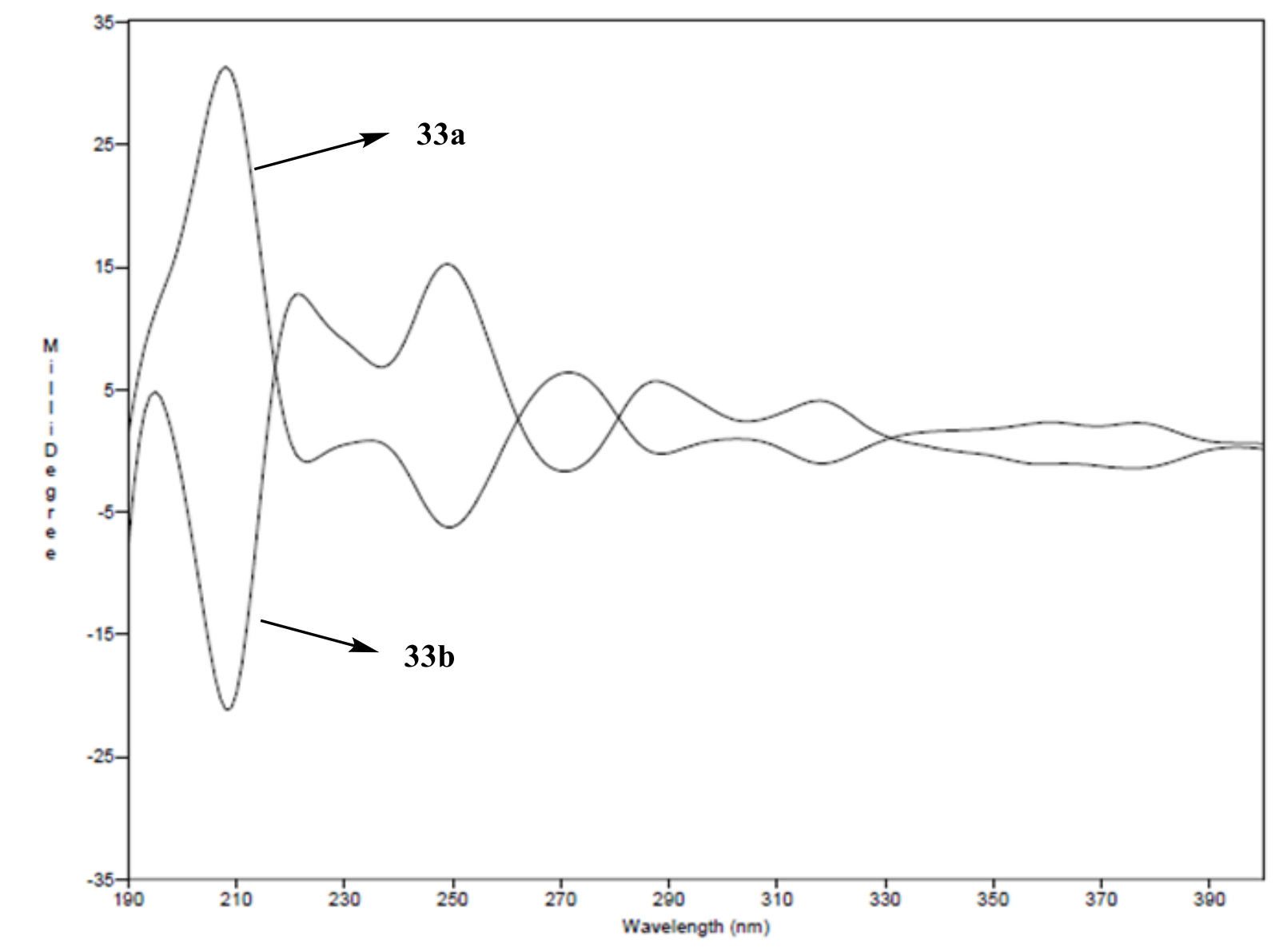

Figure S37-C. ECD spectra of 33a and 33b.

\section{REFERENCES}

(S4) Yao, S.; Tang, C. P.; Ye, Y.; Kurtan, T.; Kiss-Szikszai, A.; Antus, S.; Pescitelli, G.; Salvadori, P.; Krohn, K. Tetrahedron Asymmetry 2008, 19, 2007-2014. 
S38. Optical resolution and determination of the absolute configuration of compound $\mathbf{3 4}$.

Chiral separation of $\mathbf{3 4}$ by HPLC with $n$-hexane/EtOH (85/15) afford compounds $\mathbf{3 4 a}\left(1.3 \mathrm{mg}, \mathrm{t}_{\mathrm{R}}=39\right.$ $\mathrm{min})$, and $\mathbf{3 4 \mathbf { b }}\left(1.3 \mathrm{mg}, \mathrm{t}_{\mathrm{R}}=42 \mathrm{~min}\right)$. The absolute configurations of $\mathbf{3 4 \mathbf { a }}$ and $\mathbf{3 4 \mathbf { b }}$ were determined by comparison of the cotton effects with reference compounds. ${ }^{\mathrm{S} 4}$

(aS)-monbarbatain A (34a): $[\alpha]_{\mathrm{D}}^{20}+11\left(c\right.$ 0.1, MeOH); $\mathrm{ECD}(\mathrm{MeOH}) \lambda_{\max }(\Delta \varepsilon) 208(-23.59), 250(+19.74)$ nm.

(aR)-monbarbatain A (34b): $[\alpha]_{\mathrm{D}}^{20}-11(c 0.1, \mathrm{MeOH}) ; \mathrm{ECD}(\mathrm{MeOH}) \lambda_{\max }(\Delta \varepsilon) 207(+38.89), 250(-13.90)$ nm.<smiles></smiles>

$(\mathrm{aS})-34$

34a<smiles></smiles>

$(\mathrm{a} R)-34$

34b

Figure S38-A. Chemical structures of $\mathbf{3 4 a}$ and $\mathbf{3 4 b}$.

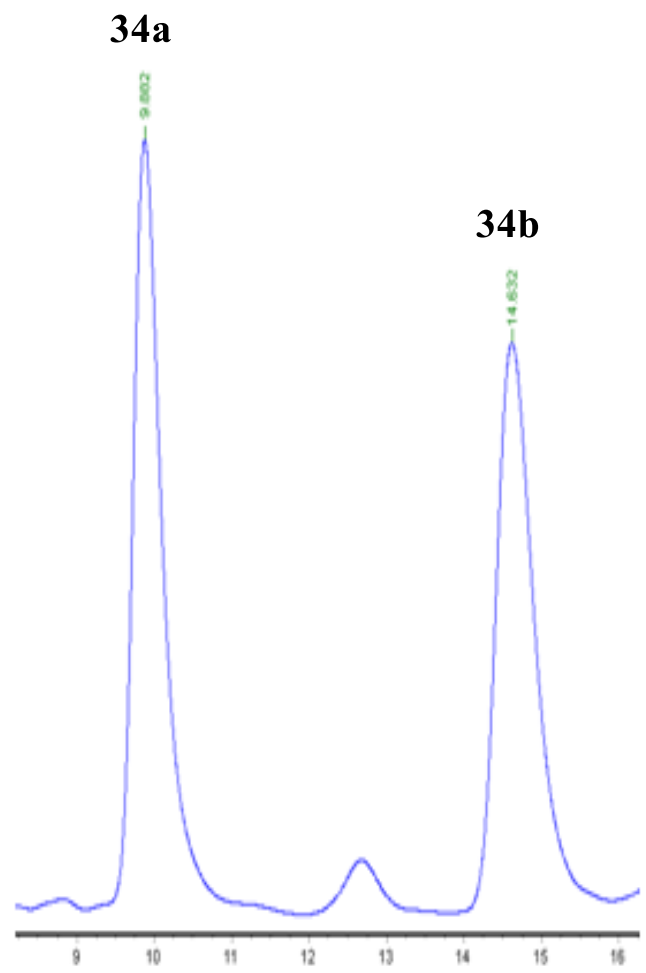

Figure S38-B. Chiral HPLC Chromatograph. 


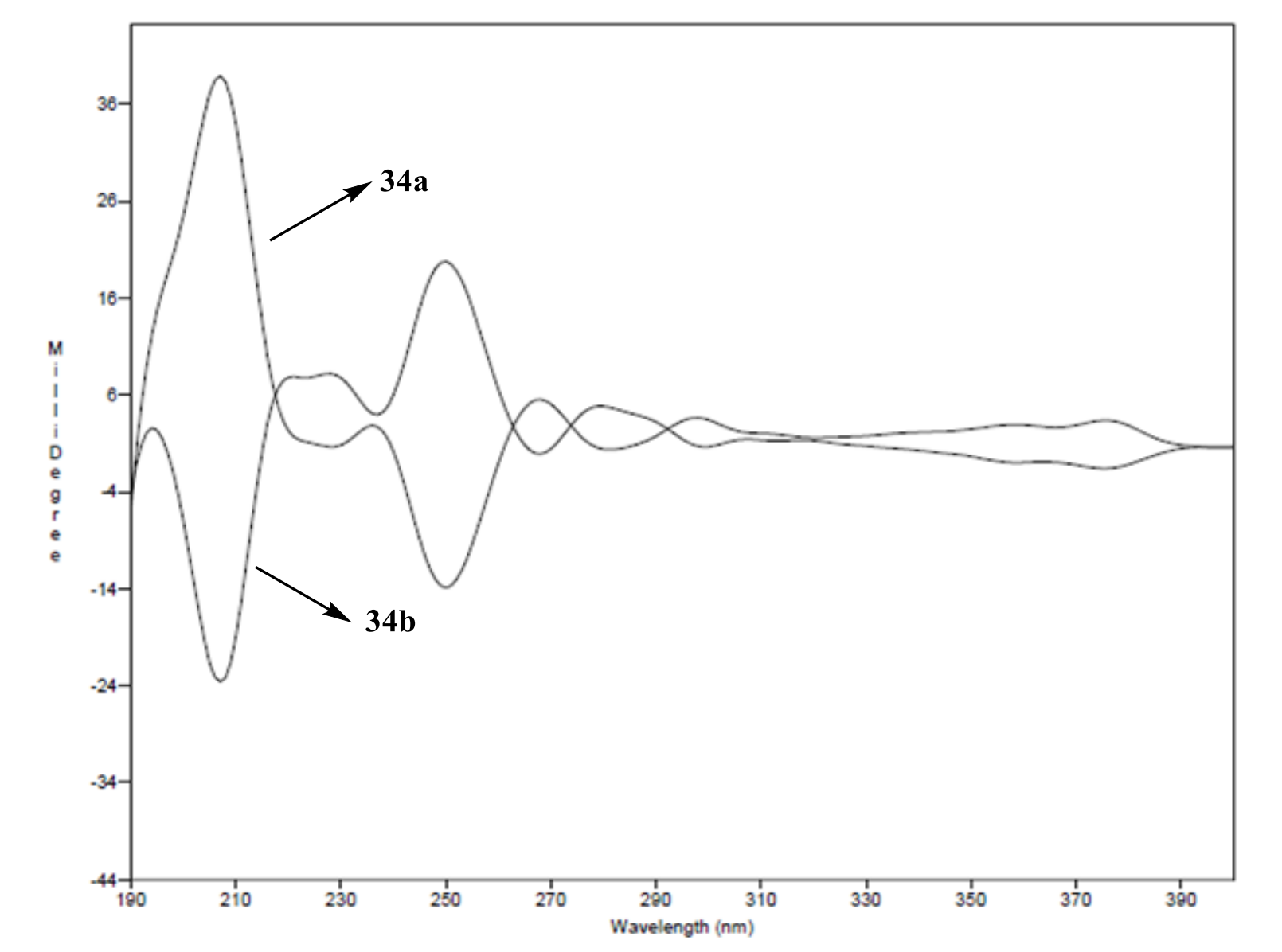

\section{REFERENCES}

Figure S38-C. ECD spectra of $\mathbf{3 8 a}$ and $\mathbf{3 8 b}$.

(S4) Yao, S.; Tang, C. P.; Ye, Y.; Kurtan, T.; Kiss-Szikszai, A.; Antus, S.; Pescitelli, G.; Salvadori, P.; Krohn, K. Tetrahedron Asymmetry 2008, 19, 2007-2014. 
S39. The experimental ECD spectra of compounds 3 (A) and 4 (B).

A:

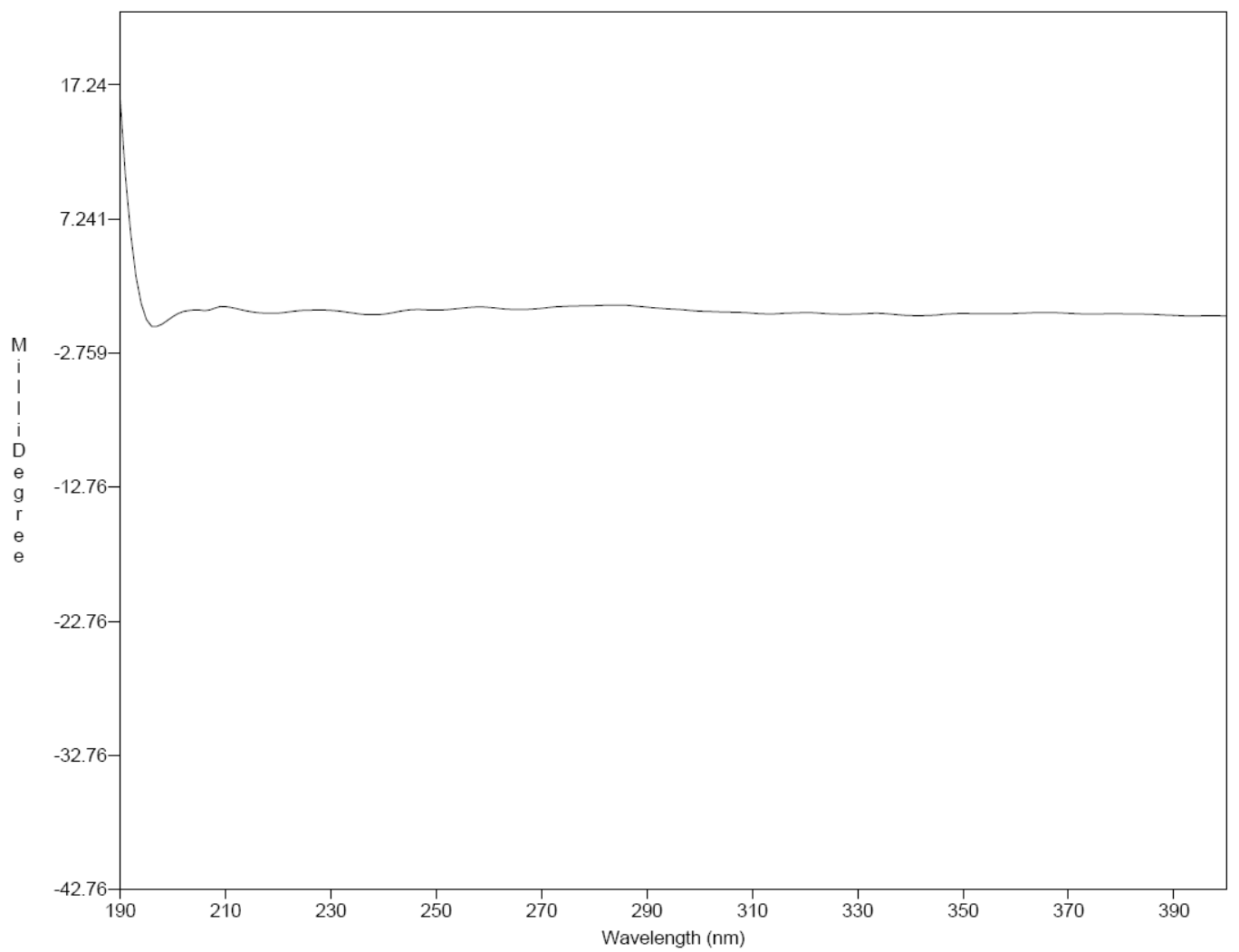

B:

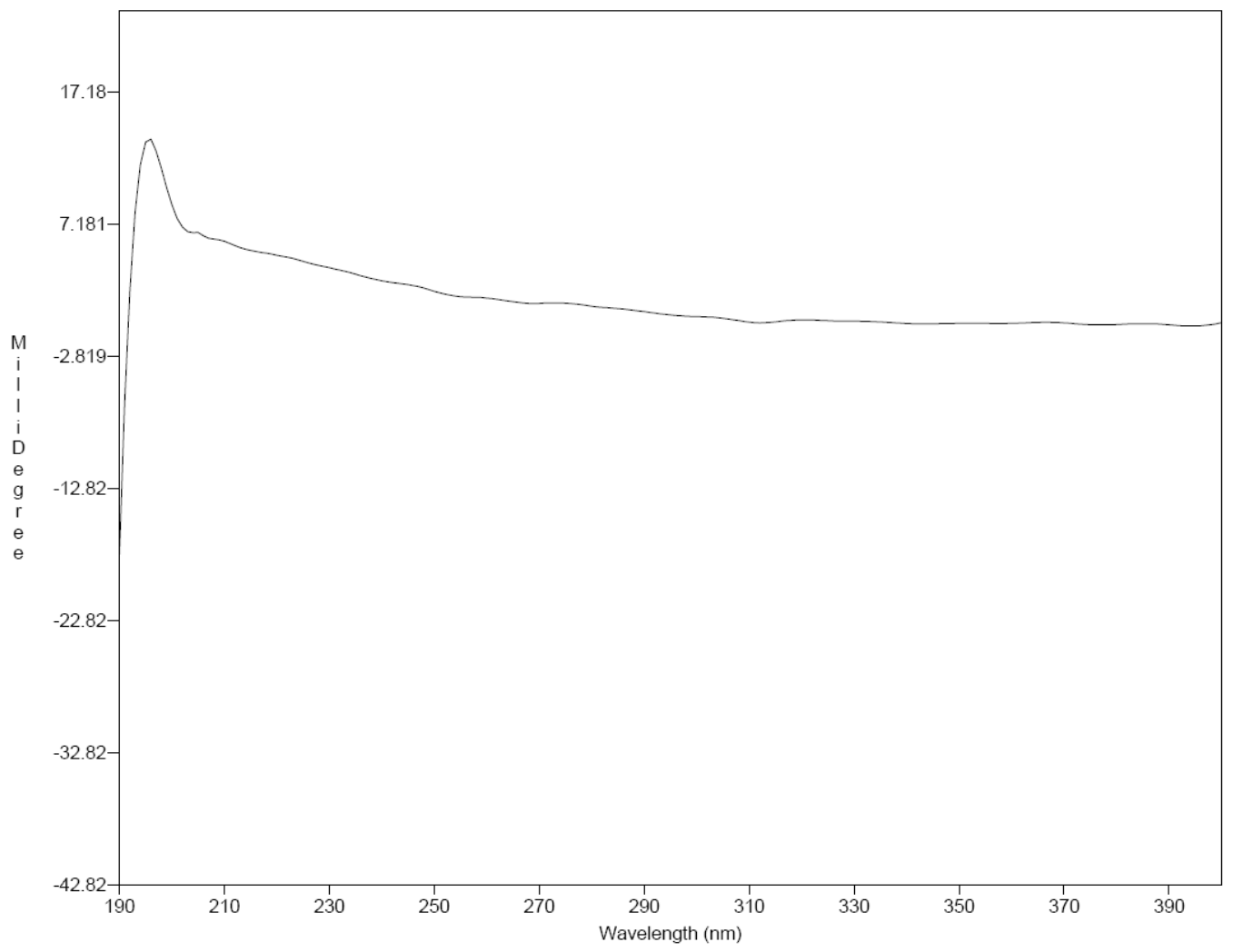

